\title{
The Sabellic accusative plural endings and the outcome of the Indo-European sibilants in Italic
}

\begin{abstract}
This work aims to clarify the phonetics and phonology of sibilants and sibilant clusters in the Italic languages, and will specifically attend to the outcomes of /ns/ and /rs/ in different positions. The structure and meaning of a number of Sabellic words and sentences will be reanalysed and reinterpreted, with a special focus on Oscan and one of its dialects, Marrucinian. An appendix containing a novel interpretation of the new «Opic» inscription of Niumsis Tanunis is included.
\end{abstract}

Keywords: Indo-European linguistics; Sabellic languages; Ancient Italy; general phonetics.

\section{Introduction $^{1}$}

The consonant system of the Italic branch of Indo-European is still subject to debate. To begin with, we have to rely, as usual, on written materials. These consist of comparatively few and often fragmentary or barely readable remains, some of which show defective spellings. Many words are attested only once, and our paradigms are often incomplete, so that new documents, however short, often come as a surprise and scramble pieces in our puzzle that we had thought were reasonably well fitted. In addition, there is no consensus as to which languages may be classified as «Italic» in the genetic, not geographical sense. In this, as in former works, I shall assume that Latin, Venetic, Oscan, Umbrian and South-Picene go back to a single ancestor which can be labeled as Proto-«Italic», and whose origins are somewhere in central or Western Europe. When or how this unity was broken is on the whole unknown, but I further take it that there have been at least two waves of advance that brought speakers of Italic into the Peninsula that gave them its name. One of them, which I dare call Latino-Venetic, may have been the earliest people of Indo-European ancestry to traverse the Alps and leave us unequivocal traces of their language and culture, albeit the existence of other substrate populations has been occasionally claimed. Over time, the impact of other Italic populations, which may be globally termed «Sabellic», severed the former continuum into two halves and settled down in Central Italy, where it underwent further dialectalisation ${ }^{2}$. Thereupon, an indeterminate number of mostly prosodic and phonetic innovations took place that affected variable areas of the Italic territory, in this way blurring the original genetic relatedness of the extant dialects beyond recognition.

This work aims to recover some of the common traits of Italic and its subgroups from a different perspective than usual. As we are going to see, both the mechanic reconstruction of a Proto-Sabellic stage and the tacit assumption that secondary, contact-induced phenomena -which changed the appearance of dialects even after thay have acquired a personality as individual entities- are scarce or dubious, may have given us a strongly biased vision of the relative chronology of Italic sound shifts. What is more, sound changes have been traditionally

\footnotetext{
${ }^{1}$ The Spanish government has (again) explicitly refused to fund this work.

2 See on this depiction of the events Bonfante (1988).
} 
taken for granted exclusively on the grounds of the apparent cognacy of forms containing them. Interestingly, however, they have never been justified in purely phonetic terms, albeit they are often based on a single example. General linguistics, including contact linguistics, general phonetics and what we know about the typology of sound change, will accordingly play an important role in my arguments. As a result, I shall not only take issue with the widely accepted views on the evolution of consonant clusters containing sibilant sounds and the resulting relative chronology, but also reexamine the way the different writing systems were used, the attribution of specific forms to a paradigm or word class, the plausibility of their etymologies and external connections, and the interpretation of the syntactic structure of the texts in which they occur.

\section{The Oscan accusative plural endings and the form iaf $^{3}$}

Two identical Oscan forms, namely Marrucinian IAFC (MV 1, Rapino, Chieti, c. 250 BC) and south-Oscan $\mathrm{t} \alpha f\left(\mathrm{Lu}\right.$ 62, Roccagloriosa, Salerno, probably $3^{\text {rd }} \mathrm{C}$. BC) are universally held to continue the acc. pl. fem. of the anaphoric pronoun ${ }^{*} i \bar{a}(n) s$. The alternative previously defended by Wallace (1985: 100, fn. 16) considered this and other forms as suggestive of the mixed ancestry of Marrucinian, which purportedly displayed Umbrian phonetic traits. In fact, this has always been exclusively predicated on the existence of U. eaf 'eas' (Um $1 \mathrm{Ib} 42$ ).

When the Roccagloriosa inscription was uncovered, the existence of the Oscan form became suddenly problematic not to say contradictory, since the finding places of the Rapino and Roccagloriosa inscriptions (respectively a lex sacra and a legal text concerning theft), are separated by more than $300 \mathrm{~km}$. The assumption of a Proto-Sabellic, that is to say, not specifically Umbrian generalisation of $-f$ as the acc. pl. ending has since become, if often not professedly, essential to salvage both the attribution of Marrucinian to the Oscan dialectal constellation and the interpretation of $\mathrm{L} \alpha f$ and IAFC as full matches of U. eaf. To my knowledge nobody has put forward a theory that questions their accepted etymology or their cognacy with the Umbrian pronoun.

The uniform, but in principle unexpected spelling $i$ - is apparently a minor inconvenience for the established etymology ${ }^{*} e i \bar{a}(n)_{s}$, but it is nonetheless surprising that this pronoun is also transmitted in Roccagloriosa B, 1. 9, in the nom.-acc. pl. neuter as عıок (cf. the formally similar fem. sg. iúk in Cm 1, Abella). In fact, it stands to reason that $\iota \alpha f$ has been written in this way because it begins by $i$-. While it is true that in the Roccagloriosa document we apparently find (few) cases of $\langle\triangleright>$ alternating with $\langle\varepsilon \downarrow>$ and $\langle\varepsilon\rangle$ to render /ẹ/from /e:/ and /i/ when flanked by consonants $^{4}$ (in fact all of them contain the pronoun $\pi \iota \varsigma, \pi เ \delta$ ), when $\langle\downarrow>$ precedes a vowel it

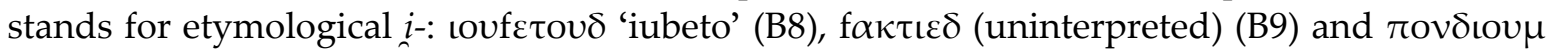
'of weights' (B11). Conversely, there is no case in which $i$ - is spelt in any other way. What is more, $e$ - in hiatus, going back to *ei- with Proto-Italic loss of intervocalic $-i-$, is never spelt $\langle 1\rangle$ in

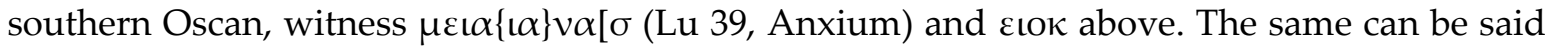
of Rapino, where IAFC, IOVES and IOVIA are in all likelihood rendering $i$-. There is consequently every reason to call into question the idea that Oscan IAFC/L $\alpha f$ is bisyllabic and begins by /ẹ/.

Before we proceed to account for Oscan iafc/ı $\alpha f$, some words are in order regarding their alleged etymology. In one of his most influential works, Rix (1986) offered two different ex-

${ }^{3}$ Unless otherwise indicated, all Sabellic texts follow ST. All texts in the Latin alphabet are in small capitals, and texts in the national alphabets are in italics.

${ }^{4}$ See McDonald et al. (2012: fn. 2). 
planations of the evolution leading to the attested forms of the accusative plural masculine and feminine in Sabellic, which deserve some comment in view of their universal success.

According to his first scenario, all but the consonant stems show a uniform Proto-Sabellic acc. pl. ending $-s$ with compensatory lengthening of the preceding vowel. Accordingly, Rix starts from the following Ursabellisch endings: $1^{\text {st }}-\bar{a} s, 2^{\text {nd }}-\bar{o} s,-i$-stems $-\bar{\imath} s$, consonant stems $e . g$. $*_{-r-n s}(>-r(e) f)$. Thereupon, Umbrian generalised the ending $-f$ of the consonant stems by a simple proportion. Oscan, in contrast, apparently conflated both allomorphs, $-s$ and $-f$, into * $f$ s. This proceeded through two stages: first, $-s$ was added to $-f$ in the consonant stems (allegedly under the influence of the dat.-abl. pl. $-f s$, which is most incredible since it would have ipso facto driven the inflection into unnatural syncretism). Second, $-f s$ was generalised to all the stems, ousting -s. Finally, $-f s$ became $-s s$ by regressive assimilation. Why this uneconomical crossing should have taken place escapes me. I believe it to be nothing but an ex post facto explanation, with the particular circumstance that there is no trace of $-f$ left in Oscan, and that the posited - $f s$ would give very marked codas in the case of the consonant stems usurs and aginss (ex hypothesi presupposing an unattested stage ${ }^{*}-r f s$ and ${ }^{*}-n f s$ ). The evolution in the feminine form must then have been ${ }^{*}-\bar{a} s>{ }^{*}-\bar{a} f s>-a s s$, attested in víass, etc. The other Oscan pronominal ending -af we are discussing remains unexplained.

Let us now take a look at the second scenario, according to which the Proto-Sabellic outcome $-f$ is regular in more inflectional types. Rix starts from the following Proto-Italic endings: $1^{\text {st }}{ }^{*}-\bar{a} s, 2^{\text {nd }}{ }^{*}-\bar{o} n s>-\bar{o} f,-i$-stems *${ }^{*} \bar{i} n s>-\bar{i} f$, consonant stems * $-r-n s(>-r(e) f)$. Thereupon, $-f$ was generalised in Umbrian, whereas Oscan, again, followed a different path: It is fundamentally the $1^{\text {st }}$ declension ending * $\bar{a}$ s (and presumably the diphthongal stem * $g^{u}$ ouns $>^{*} b \bar{o} s$ ) that triggered the spread of $-s$ to the rest of the forms, giving rise to $2^{\text {nd }}{ }^{*}-\bar{\rho} f s$, consonant stems ${ }^{*}-r(e) f s$, and then, in a completely unnecessary turn of the screw, was contaminated by these and corrected into *a $f_{s}$, eventually yielding -ass. It should be noted that Rix believes compensatory lengthening to have taken place at the stage in which the cluster - ns still existed, which thereupon evolved into $-f$. I find this incredible, in spite of the phonetic account that he offers in passing some lines before (1986: 586): «Primäres und sekundäres - $n s$ ergaben dann schon ursabellisch $-f$, wohl über $-n p>-n f$ (oder eher, was hier nicht zu diskutieren ist, über $-n z-n \delta-n f>-b$ )», which tiptoes around the problems of the nasal-to-fricative transition I shall review below, as well as the unlikely voicing of fricatives after nasals, and offers no parallels for the proposed changes.

Again, the pronominal ending - af was disregarded by Rix, probably under the tacit assumption of Umbrian influence or appurtenance, which as we have seen is no longer acceptable. Firstly, there is no explanation for the fact that the pronoun shows a different ending from the noun. Secondly, the phonetic side cannot be right: if one gives any credit to Rix's first scenario, the pronominal ending - af would have come into being by way of substitution (in analogy to the consonant stems) followed by preservation of $-f$ in the pronoun as opposed to addition of -s to the noun stem, which is not the tenor of Rix's account and makes no sense. Following his line of reasoning, by contrast, it is impossible to come to terms with our pronoun, since the ending -s has been pervasively replaced by $-f s$. This, in turn, means that *ệfs has unaccountably lost its $-s$ instead of evolving into tẹāss. Things fare no better for Rix's second scenario, which demands that pronominal $-\bar{a} s$ first contaminated the rest of the paradigms, then was changed into $-\bar{a} f s$, only to lose its final distinctive $-s$ in this particular pronoun only. As a consequence, Rix's strenuous achievement of a uniform acc. pl. ending is distorted by an unexplained, nonphonetic turn of events which arbitrarily introduced an otherwise unattested plural ending ${ }^{5}$.

5 This account is generally and rather uncritically accepted as far as I know (e.g. WOU: 356, Tikkanen 2011: 33), and not refuted, at least in its general lines, by Clackson (2013: 28-29), who simply remarks that, in view of 
Finally, the acc. pl. fem. ekass, ekask 'these' (Po 1, 14, Pompei) discredits the idea that IAFC and t $\alpha f$ contain an acc. pl. ending beyond any shadow of doubt. There is a sequence fitias estas amgenas in South-Picene (Sp AP 3; IItal. I: 183, Falerio 1) which could be a phrase in the acc. pl. fem. including a pronoun estas and thus revealing another Sabellic case of pronominal $-\bar{a} s$, but this cannot be proven beyond doubt (Dupraz 2012: 38).

As a consequence, the very idea that the Oscan accusative plural feminine ever contained $-f$ is a matter of personal belief. It is based on a number of requirements, none of which is unassailable: a) the input for the whole process must be ${ }^{*}-n s>-f$. This change goes first in the diachronic sequence of shifts leading to the attested forms, and consequently necessitates a primitive, unitary output; this is placed in a canonical Proto-Sabellic stage in Rix's rigidly genealogical conception of language relatedness; b) the secondary shift * $n t s>-n s s>-n s>-f$ is shared by all the Sabellic languages and therefore must also be situated as early as Proto-Sabellic; c) all this happened before final vowel syncope, and in this way the nagging obstacle of a potential phonetic merger of $-n s$ with postsyncope $-n(V) s$ can be circumvented.

As implied above, Rix's ideas on the history of the Oscan accusative plural endings are in his view borne out by the abl. pl. ${ }^{*}-f_{0 s}>-f_{S}>-s s$, but the comparison is off the mark. To begin with, there is no single case of an acc. pl. preserving the cluster $-f_{s}$ which, as we have seen, is an essential intermediate stage in both variants of his reconstruction. Next in Rix's argument comes a subtle phonetic fallacy: while the sequence -ss in the abl. pl. is obviously the product of assimilation, it is not directly indicative thereof, since in all likelihood it is synchronically marking a tense sibilant of whatever origin in word final position. To account for the fact that *-ns\# gave rise to a tense sibilant [s:] in Oscan and [f] in Umbrian and South-Picene, we have to take a fresh look at the phonetic reasons behind the divergent evolutions. But first of all, I shall try to make sense of iaf.

\section{Oscan iaf revisited}

What the forms IAFC and $\mathrm{L} \alpha f$ have in common is the fact that they precede a verb in the $3^{\text {rd }}$ person singular, and that this verb is in both cases in the future tense, respectively FERET ${ }^{6}$ and $\kappa \lambda$ отои $\tau \tau$ (see below 3. for a more precise description of the syntax of these texts). The only Oscan form that could conceivably end up in -af and, additionally, could agree with such a verb form in person and number, is an active present participle bearing the suffix - nt-, a category thus far attested in Oscan kúnsif (IItal. II: 1183, Pentri/Terventum 22), the unclear statíf (Sa 1, Agnone), and possibly in the disputed form staef 'standing' (if < *sta-e-ent-s), as per Rix (1986: 596), WOU: 697, but recently read as ta<v>ffúd (IItal. II: 895, Capua 22). The outcome $-f$ is shared by Umbrian, as in zeřef 'sedens' (Um 1 Ia 25, 33, 34), restef 're-stans, restoring?' (Um 1 Ib 9), kutef 'in silence (Um $1 \mathrm{Ia}, \mathrm{b}$, passim). I consequently trace iaf back to Proto-Italic *iant-s, and further identify this form with L. iēns, Ven. ia.n.t.s. (personal name, Vicenza, LV: 124), Skt. yant-, Gk. i $\omega$ v, possibly Hitt. iiant- 'sheep', ultimately from IE * $h_{1} i-e n t-s,{ }^{*} h_{1} i-n_{0} t-$.

Athematic root participles are a dying category in Italic, and Latin preserves only a few, like the lexicalised forms cliēns (see Fortson 2017: 842), as well as probably parēns (EDLIL: 445446). A number of them is preserved in the onomastic corpus of Venetic, for instance the per-

IAFC/L $\alpha f$, the process must have been more complex than envisaged by Rix. One does not easily see, however, how it could be still more entangled without calling to question the basics of historical morphology.

${ }^{6}$ If it goes back to an athematic form *feresti like U. ferest (Um 1 IIa 26) with weakening of /s/ in coda position. Alternatively it may be a $3^{\text {rd }} \mathrm{sg}$. present indicative. 
sonal name in the dative La.n.te.i. (Padua). In their edition of this text, Marinetti et al. (1994: 189-190) mention similar names, like Vants and Iants, but offer no account of their make-up beyond the purely descriptive information that they contain «Ca+-nt-». In fact, La.n.te.i. may continue a root participle *ulant-, from ${ }^{*}{ }_{n} l H-n t-$ 'ruling' 7 . Any attempt to come to terms with the unexpected phonotactics of this and similar forms containing ${ }^{*}-1 / r H-n_{0}$ - has proved futile in the past: the expected outcome of * $u_{\sim} \mathrm{H}$ - not- is *ual-ant-. As in the case of *trH-not- 'through', reflected in L. trāns, U. traf 'through' and OIr. trá 'so, indeed', we probably have to reckon with early laryngeal resyllabification into ${ }^{*} \mathrm{ulH}_{\mathrm{o}}-n t-,{ }^{*} \mathrm{trH}-\mathrm{nt}$-, etc. ${ }^{8}$ In addition, La.n.te.i. cannot possibly be a Celtic form, or it would have been adopted in Venetic as tflant-. Finally, Vants, Vanta, etc. (personal names, $L V: 9,53,78$, Este) come from ${ }^{*} g^{u}(e) h_{2}-n_{o} t-$ 'going', attested in Gk. $\beta \bar{\alpha} \varsigma$. Whether all these onomastic remnants of aorist participles reflect synchronically living verb forms is impossible to ascertain, but on the most likely assumption they were already archaisms, and their systematic replacement by other forms that conduced to a drastically reduced system with one single active participle for all stems had begun long before our first attestations.

It has recently been proposed (Prósper 2018a) that the universally accepted idea that all the Italic languages except Latin and Venetic have remodeled the endingless nom. sg. $-\bar{o}(>-\bar{u})$ of the masculine nasal stems as ${ }^{*}-\bar{o}-n s$ somewhere down the line is erroneous: This is not the case in South-Picene, where in my view we find a nasal stem panivú 'monument' (and not ** panivúf) that agrees with an adjective meitims 'most gentle, best' in the nom. sg. masculine (Sp TE 5, Penna Sta. Andrea) ${ }^{9}$. It is not proven that Umbrian partakes of this analogical extension, either, since the relevant forms show no ending: cf. tribriçu 'trinity' (Um 1 Va 9) and karu 'meat' (Um $1 \mathrm{Va} 24,27, \mathrm{Vb} 4$ ). In my view, the Oscan nom. sg. in -uf is definitely not the outcome of earlier * $n s$, but simply the product of the spread to nasal stems of the ending $-f$, which could only go back to * $n t$-s. Moreover, O. $-u f$ is only attested with absolute certainty in one document from Campania, and only in *-(t)i-o, $-(t) i-n$ - stems: fruktatiuf 'use, enjoyment', úittiuf 'use' and tríbarakkiuf (Cm 1 A21, B14, A11-12, Abella). In other words, the spread of $-f$ is comparatively late and contributes nothing to the resolution of the chronological problems of the acc. pl. endings. This morphological innovation, whatever its causes, is not even certain to encompass the whole of the Oscan territory: if Marrucinian BABV is a nasal stem, it has not undergone this innovation, either (see immediately below). In turn, we have to reckon with the possibility that the intrinsically unstable sequence *-nt-s was restored in the individual dialects. But, if what we actually find is the direct, expected Sabellic outcome of * $n t-s$, this would only mean that this particular sequence, which was unique in containing a complex coda with a segmental /t/ and word-final /s/, became $-f$ early on. In spite of Rix's convoluted arguments, there cannot have been a Proto-Sabellic evolution *-nts $>^{*}-n s s>^{*}-n s>-f$ (which actually goes counter to universal phonetic tendencies) and consequently it cannot be detrimental to my starting point that the Oscan and Umbrian acc. pl. endings have no common source *-ns $>-f$ in any inflectional stem.

${ }^{7}$ A sequence \#ulV- was simplified early in Italic, as transpires from Ven. leno (LV: 12, 14, 25, Este).

8 Sergio Neri (Munich) has kindly made the point to me that he would reckon with the inversion of Lindeman's Law in this case, by which an unstressed epenthetic vowel ${ }^{*} C R H V->{ }^{*} C \partial R V$ - would be syncopated in a trisyllabic form, giving *CRV-: e. g. dat. *uloh ${ }_{2} n t$-éi > *ualngt-éi > *unlnot-éi . Cf. Neri (2019: 50).

${ }_{9}$ A kind reviewer reminds me that the ascription of SP. panivú to the nasal stems is not assured. However, even if the following form meitims were not a superlative adjective as I contend, but a noun, both a credible attribution of panivú to another paradigm, or an alternative syntactic analysis that invites one to consider its inclusion in a different word class, are lacking. At all events, the burden of the proof still falls on those postulating the addition of $-f$ to nominatives of nasal stems in Proto-Sabellic. 
Now to the semantics of iaf: if we had to translate this sequence of present participle + verb in personal form into a modern European language, we would have to resort to a verbal hendiadys or pseudo-coordination by which two consecutive verbs, the first of which is often a verb of movement which becomes grammaticalised, come to express one single state of things, and no longer a sequence of separate but related events. The first verb comes to be superfluous and only emphasises the voluntary nature of the action, and thus underscores the subject's decision to do something: the subject is animate and acting both intentionally and immediately. In essence, the whole construction refers to a single event ${ }^{10}$. But by using it, they speaker may even be going so far as to decry this event as too daring or even paradoxical. In modern languages, both verbs are coordinated and used in personal form and agree in tense and mood, as in 'he goes and says' (a variety of expressions of this kind is also quite common in English: see Stefanowitsch 2000), Sp. 'coge y se va', It. 'prendo e me ne vado'.

This construction is usually, though not universally, and not exclusively, ingressive, and at all events the inclusion of the first verb form is only intended to modify the inner aspectuality of the second. On the pragmatic side, it has taken on some vulgar nuances. On the other hand, the process of grammaticalisation is often not completed, as transpires from the fact that an array of introductory verbs can be used according to the degree of expressiveness, and that the superfluous verb may even take a direct object. Besides the Western European languages, this construction is well known in the Balkans, specifically in Medieval Greek, in which constructions with $\pi \iota \alpha \dot{\alpha} \omega \omega$ and $\alpha \varrho \chi i \zeta \omega$ are found. In some languages like Rumanian, the construction can be paratactic and the conjunction can be omitted (see Wagner 1955). By contrast, the introductory verb has been fully grammaticalised in Arabic, to the point of becoming a particle, as in the ingressive particle of verbal origin $q \bar{a} m$ 'get up' and its dialectal variants, which modify the aspect of the main verb and can be freely translated as 'suddenly' or 'without delay' (Naïm 2016: 349-353).

The participial construction illustrated by Oscan iaf $+3^{\text {rd }}$ pers. verb is, mutatis mutandis, the hypotactic equivalent of this structure, and is known to have enjoyed currency in Ancient Greek: for instance, Coseriu (1936: 53) drew attention to the "pleonastic use of $\lambda \alpha \beta \omega v$ » attested from Homer onwards; he even thought that the modern paratactic construction can be traced back to the hypotactic one, which conveys a similar meaning: cf. $\tau i$ i $\mu$ 'où $\lambda \alpha \beta \omega \dot{v}$

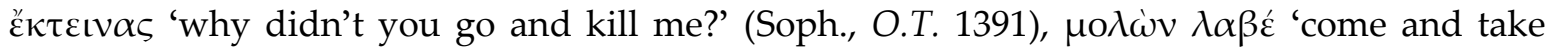
them (the weapons)' (attributed to Leonidas at Thermopylae by Plutarch, Ap. Lac. 225c),

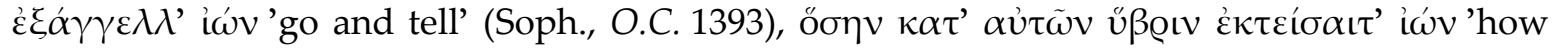

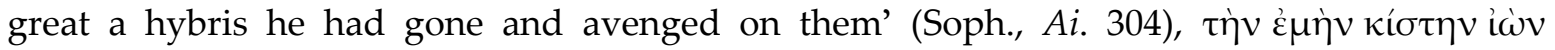

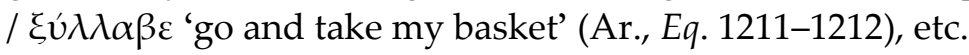

Since we lack anything near a real corpus of Italic texts containing this or similar expressions, we are at a loss as to how far the process of grammaticalisation had progressed, whether other auxiliaries carrying different pragmatic nuances could be employed, or, at the opposite end of the scale, whether iaf had been fossilised into an ingressive particle. Finally, Greek influence from Magna Graecia that could have contributed to the development of this structure cannot be ruled out ${ }^{11}$.

${ }^{10}$ For instance, the dictionary of the Real Academia de la Lengua Española (ed. 1992) includes this as a secondary meaning of coger 'to get, catch': «unido a otro verbo por la conjunción $y$, decidir y cumplir inmediatamente la acción significada por éste».

${ }^{11}$ In point of fact, since the hypotactic construction is alien to Latin syntax, Coseriu points to Late Greek as the model for the paratactic construction in the Romance languages, especially as regards the Italian dialects and Rumanian. 


\section{The text architecture of Roccagloriosa and Rapino}

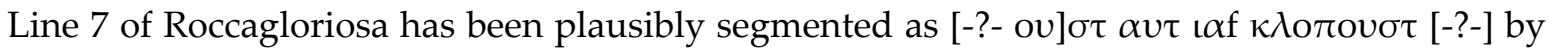
Rix ( $\mathrm{Lu} \mathrm{62),} \mathrm{who} \mathrm{in} \mathrm{this} \mathrm{way} \mathrm{privileges} \mathrm{one} \mathrm{of} \mathrm{the} \mathrm{alternative} \mathrm{segmentations} \mathrm{considered} \mathrm{by} \mathrm{the}$ original editors (see Poccetti et al. 2001: 220-222). They had correctly favoured this analysis, but called for prudence regarding the interpretation of $\mathrm{t} \alpha \mathrm{f}$ as an acc. pl., in view of the spelling (for expected $+\varepsilon\llcorner\alpha f$, see above), and because it crucially differs from the Oscan synchronic ending -ass and consequently has to be regarded as a remarkable archaism (whatever that means since, as we have seen, no theory of the diachronic evolution of this ending, however elaborated, has been able to accommodate this form thus far ${ }^{12}$. The translation offered by McDonald et al. (2012: 32) reads: 'he shall have [-?-] or he shall have stolen them (fem. pl.)'.

My own, alternative translation would provisionally run as follows: 'whoever/if somebody should [...] or should intentionally steal [...]' (with a DO in the lost part). In the preceding section of the text there is no single form to which an anaphoric pronoun $\mathrm{t} \alpha \mathrm{f}$ could refer, but this can be put down to the unknown number of letters that have been lost. At all events, if the two perfective futures are paratactically coordinated and stand in immediate proximity, and further precisions that would separate them and hamper comprehension are lacking, the anaphoric reference to the DO does not seem indispensable. One thing seems clear to me: the active participle underscores the intentionality of an illegal action, which for this very reason is not simply an action, but the commission of an offence. In essence, the participle points to premeditation, and the legal consequences require that the action has been completed, which explains the future perfect.

The bronze tablet of Rapino is conducted in Marrucinian, plausibly defined as a northern Oscan dialect. It raises many different questions relating to ritual and even to the divinities involved, and its reading is far from clear, since all we possess are drawings and the original document was lost in WWII. In contrast, its syntax seems to be comparatively unproblematic for current scholarship, not least because the transmitted text has been subject to a number of «improvements». I shall argue, however, that the accepted translation is the product of a chain of misconceptions affecting the central part of the document, and that a more elegant account can be reasonably defended. It is impossible in a single study to do justice to all the previous interpretations, and my analysis will zero in on the problems posed by lines 5-10. This part, which arguably depicts the second stage of the ritual, pivots around the form IAFC, which, as should be clear by now, has been unanimously interpreted as a feminine pronoun in the acc. pl. The text reads (according to Mommsen 1846):

AISOS PACRIS TOTAI / MAROVCAI LIXS / ASIGNAS FERENTER / AVIATAS TOVTAI / ${ }^{5}$ MAROVCAI IOVES / PATRES OCRES TARIN/CRIS IOVIAS AGINE / IAFC ESVC AGINE ASVM / BABV POLEENIS FERET /

${ }^{10}$ REGEN[--] PEAI CERIE IOVIA / PACRSI EITVAM AMATEN/S VENALINAM NI TA[G]A NIPIS PED/I SVAM

As in Roccagloriosa, the spelling is IAFC, and not $\mathrm{EEAFC},{ }^{13}$ and it precedes a $3^{\text {rd }}$ person singular future verb form. In Rapino at least, the construction might be fully grammaticalised, which would account for the use of enclitic $-k$ (possibly also present in Roccagloriosa if we had

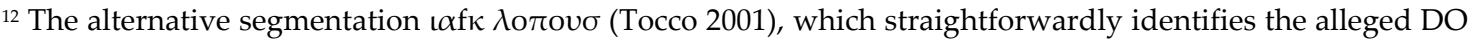
with Marrucinian IAFC, can probably be disregarded, but see immediately below. See more recently McDonald et al. (2012), with a discussion of former views, the interpretation of Roccagloriosa as a legal text concerning theft and its consequences.

${ }_{13}$ Anyway, raising of /e/ in hiatus after early loss of intervocalic - $i$ - could justify this rendition, since the whole document has $<\mathrm{p}$ for /ẹ/. 
to read $\iota \alpha f(\kappa) \kappa \lambda o \pi o v \sigma \tau$ with omission of the first $-\kappa)$, which served an emphatic or demarcative function that reinforced the syntagmatic unity of participle and the verb ${ }^{14}$. And then, IAFC/ $\operatorname{l} \alpha(\kappa)$ would have become little more than an adverbial, synchronically marking ingressive aspect. In that case, it would be no different from the external aspect marking in Arabic dialects. As implied above, it is difficult to say whether we are speaking about a syntactic calque from the Greek dialects of Magna Graecia but this possibility cannot be rejected out of hand.

The sentence IAFC ESVC AGINE ASVM BABV POLEENIS FERET is variously translated, $e . g$. as 'eas hac pompa *asum Babo Polenius fert' (Bottiglioni 1954: 331), and more recently as 'these, in the ceremony of these, the Babu, the poleenis, take [them] to roast [them]' (Dupraz 2012: 193), and 'at the festival of these (divinities) babu polfenis (or babu and polfenis) will carry these (perhaps pieces of meat) for roasting (asum)' (Weiss 2010: 136-137, fn. 58). Naturally, the only reason to view ESVC as a genitive plural form is the prior assumption that we have already found the DO of FERET. But, if IAFC is ruled out as an acc. pl., the only forms that qualify to replace it in the unoccupied syntactic slot are ESVC and ASVM.

Some words are in order as to the intrinsic plausibility of identifying ESVC as a genitive plural form, which crucially hinges on the identification of its stem. It is usually held to be an anaphoric pronoun going back to *eiso- (see Dupraz 2012: 195-196). Here is where we find the first obvious obstacle: There must have been either monophthongisation, by which /ei/ yields /e:/ contrary to expectations, or a misspelling, by which $<\mathrm{I}>$ has been simply omitted. Neither assumption is especially problematic, since 1.1 reads TOTAI for TOVTAI, but both require special pleading, and a solution that respects the extant text is preferable.

Secondly, the text is said to refer to a number of divinities mentioned two lines above, which justifies the genitive plural ESVC. But this is by no means an unassailable idea, either. In fact, the only divinity mentioned in direct connection to the ritual is IOVIA, an epithet that can refer, as traditionally contended, to Demeter, but also to the goddess who was her child by Iuppiter, that is to say Persephone. The only possibility of finding more than one divinity to which ESVC could refer is to coordinate IOVIAS with IOVES PATRES and make both depend on AGINE; this is syntactically uncompelling and makes the syntax of the whole text intractable, and it is intriguing that Iuppiter is never mentioned again. As we are going to see, IOVES PATRES depends on TARINCRIS. Accordingly, the reference is to one, not several divinities. This is independently suggested by the corollary IOVIA PACRSI which, despite the repeated attempts to correct it into IOVIAI, means nothing but 'may Iovia be favourable' 15 .

Thirdly, even under acceptance of the above premises, ESVC is undeniably superfluous from a pragmatic point of view: The reader does not need to be reminded of the destinataries of the festival, ex hypothesi Iuppiter and Iovia, nor does their festival need to be distinguished from another one in such a short inscription and in an otherwise unambiguous context. In sum, the translation «in the festival of these» entirely relies on the premise that ESVC must be a genitive plural because IAFC must be an accusative plural because it must anaphorically retrieve ASIGNAS.

I would naturally derive ESVC from *ekso-. According to Dupraz, there is no single anaphoric example of this pronoun. As we have seen, this compels him to accept a monophthong-

${ }^{14}$ As in English 'now he goes and says', Sp. 'y/pues va y le dice'.

${ }^{15}$ What is more, the preceding part reading REGEN[--] PEAI CERIE may also refer to her as a Cerean divinity, since she is Ceres' daughter, but the ending is difficult to assess (see Rocca 1997; Prosdocimi 1997). The readings differ substantially at this point, and we have ST: REGEN[EI] PEOI CEREI IOVIA PACRSI; IItal.: REGEN[EI] PIOI CER<EI> IOVIA $<P>$ PACRSI (accepting the conceivable but unwarranted correction to CEREI IOVIA $<\mathrm{P}$ by Meiser 1987: fn. 51). This problem lies beyond the scope of this work. 
isation of *eiso- for the Marrucinian form (2012: 200), a possibility gainsaid by EITVAM. Note that the idea that ESVC AGINE is a phrase with both forms agreeing in the abl. sg., meaning 'in this festival' vel sim. (see recently Rocca 1997) ails from the same problem: either the pronoun has undergone monophthongisation or its anaphoric nature is not guaranteed ${ }^{16}$. But then, this may not be an anaphoric pronoun. It could be a text deictic ablative * $e k s o \bar{o}-k(V)$ ' with regard to the above' > 'accordingly' or even 'thereupon, from there on', in agreement with the sense reconstructed by Dupraz for *ekso-.

In turn, the hitherto non-negotiable interpretation of IAFC as an acc. pl. introduces distortion in the following section of the text, since no other accusative is expected to occur after IAFC. In order to bypass this objection, ASVM has been understood as a supine ${ }^{*} a d-t u-m$ 'in order to roast', which expresses the purpose of the action and goes back to the accusative of an action noun, of which IAFC is the DO: 'in order to roast them', 'for them to be roasted'. By this expedient, the problem inherent in the lack of agreement vanishes. The resulting construction is then compared to similar Italic ones, like L. ad visitatum Ciceronem or U. anzeriato avef 'in order to watch the birds'.

All this is unnecessary if we start from the idea that IAFC agrees with the subject of the sentence, BABV, and ASVM is a substantivated participle *ad-to- in the acc. sg. neuter that naturally takes its place as the DO of FERET. If ASVM is a match of U. ASO (Um $1 \mathrm{VIb}, 50)$ and L. assum 'roasted', the meat is not taken to be roasted at the feast; on the contrary, once the meat has been roasted, it is taken to be offered to the divinity. Nonetheless, the meaning of U. ASO is unclear. The sentence reads ERIHONT ASO DESTRE ONSE FERTV, translated by Weiss as 'the same person should carry [...] on the right shoulder'. Weiss opens up a number of interpretations for ASO, some of them unrelated to roasting (which is not favoured by the general context), and even proposes a meaning 'axe' (*akso-). The Umbrian and the Marrucinian sentences look amazingly similar in that Umbrian ERIHONT (a hapax) is the subject, ASO the DO, FERTV (fut. impv.) vs. FERET a verb that indicates that someone should bring something, and DESTRE ONSE vs. POLEENIS the way or instrument in which it should be carried. In the second case, POLEENIS stands in the abl. pl., and then, contrary to previous assumptions, it is not a nom. sg. of an adjective or family name in *-iios agreeing with the subject BABV ${ }^{17}$. There is little more that can be said about this with any degree of certainty, except that both ASO and ASVM are accusatives, both occur as a DO, and both could designate the same thing. To recap, I translate the sequence as 'the babu shall thereupon go and carry the roasted? (meat) at the feast in arms/trays? (as an offering) to [...]'.

Let us now take a look at the immediate antecedent of this sentence. TARINCRIS is nearly unanimously believed to be the gen. sg. of a place name in apposition to OCRIS or a divine

${ }^{16}$ Note the problems surrounding the origins of the ending $-<\mathrm{E}>$ of AGINE: if it were an ablative, we would expect TAGINVD. And if it was a locative ending (whatever the synchronic value), the locative PEDI in the last line would be unaccounted for. Accordingly, this is an instrumental $-\bar{e}$ from IE ${ }^{*}-e h_{1}$, as reconstructed for the Umbrian ablative - $e$ (Rix 1994: 26), Tikkanen (2011: 29). According to Meiser (1987: 112) it is down to the alleged SouthPicene substrate. On the most economical assumption, it is suggestive of a Common Sabellic ending ${ }^{*}-\bar{e}$, only later replaced in Oscan by the thematic ending, but preserved in peripheral Oscan varieties (the same would apply to Pael. AETATE).

${ }^{17}$ One can hardly resist the temptation of identifying the protagonist of this ritual with Greek Baubo, also attested since Hellenistic times as Babo, originally an old woman who, according to the myth, managed to make the distressed goddess Demeter laugh. This character is also found in the form Babo on inscriptions as the receiver of cult beside other divinities (IG V: 12, 227), and still present nowadays in fertility folk rituals held in Thrace and Greece, where she (or he, since it is often a man in the guise of a woman) carries a basket or a cup. The appearance of a character with mythological associations is easier to explain than an otherwise unknown personal name, devoid of the slightest hint of an Italic ancestry and unexpected in a ritual prescription. 
name agreeing with IOVIAS. Meiser (1987: 113, fn. 50) stated that there is no paradigm of which this form could be the genitive and corrected into TARINCRIIS, which is entirely unwarranted ${ }^{18}$. What is more, the resulting syntax has never been cogent. These are some of the advanced translations: Pisani (1953: 115): «Prosiciae ferantur auspicatae civitati Marrucinae Iovis patris ocris, Tarincris Ioviae pompa» (una località chiamata Tarincris Iovia). Vetter (1953: 153) does not fare better when he translates «non prosectae accipiuntur a marruco populo Iovis patris arcis Tarincris Ioviae causa». More promising is Bottiglioni's approach (1954: 331), who translates «Iovis patris ocris Tarincribus Ioviae pompa». More recently, IItal. I: 232 is both noncommittal and forced: 'the portions [...] by the pronouncement (?) of Jupiter the father - of the Tarincrine Mount - (and of) Jouia, are brought'.

The correction of TARINCRIS into TARINCRIIS has proved, if anything, detrimental to the global comprehension of the text. TARINCRIS can be taken at face value as an appellative noun in the ablative plural, and the sequence IOVES / PATRES OCRES TARIN/CRIS IOVIAS AGINE can be translated as 'in the festival of Iovia, (held) at the top of the hill (= acropolis) of Iuppiter'. This is consistent with the fact that Italic cult sites were often situated in peaks, especially those related to Iuppiter. TARINCRIS 'high-mount?' is a compound similar to L. mediocris 'middle-

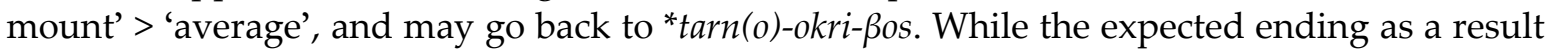
of final vowel syncope and assimilation is -iss, it has passed largely unnoticed that this document simply does not use double spelling, and consequently does not note geminates, nor, as in this case, the difference between tense and lax sibilant sounds. Medial syncope would have had the same effect as in O. patensíns $<{ }^{*}$ patnsse-- $<{ }^{*}$ patna-sē-, but the resulting form would have undergone context-sensitive raising ${ }^{*}$ tareykri- $>$ tarinkri-, and is in this respect comparable to ASIGNAS (-sinn- <*-segn-). The form Tadinates occasionally brought to bear on this matter (under the assumption that its base might have been rhotacised in Marrucinian) is in all likelihood unrelated.

The nearest cognates of TARINCRIS are BToch. tarne 'summit, peak', Hitt. tarna 'head, skull', from *tr(H)-no- (see DTB: 298, EDHIL: 845-846). DTB quotes a suggestion by Craig Melchert to the effect that both forms could be grouped under a single preform ${ }^{*}+r H-n o-$. In that case, the Italic form would become their full match under the modified version of the «palma»-rule, according to which ${ }^{*} \mathrm{Cr}_{0} \mathrm{H}$.CV- yields Italic ${ }^{*} \mathrm{Cár}$.CV- (see Prósper 2020). TARINCRIS consequently meant 'high-mount?' and designated the summit of a hill devoted to Iuppiter in which the rites were performed.

\section{The fate of Indo-European sibilants in Oscan: an overview}

At this point, it is necessary to revisit the Oscan phonemic system, which must be established starting from documents attested in three different alphabets and is fraught with indeterminacies and apparent contradictions, especially as regards sibilants (cf. Lejeune 1970; Zair 2016). Even factoring out scribal errors or hesitations in the rendition of geminate segments, the extant testimonies are compatible with the following scenario:

a) Oscan had a lax phoneme /s/ that was contextually realised as a voiced [z] (in intervocalic position, in coda position before a sonorant or a lax/voiced obstruent, and in postsyncope onsets after a sonorant) or as a voiceless $[\sigma]$ (in coda position before a tense/voiceless obstruent, in auslaut, or in internal post-syncope onsets after voiceless stops). The latter variant may have been prone to aspiration and eventual effacement.

${ }^{18}$ Cf. MV 1, IItal. I: 231, WOU: 735. 
b) In early Oscan, /s/ stood in contrast with a tense /s:/ which mostly went back to clusters. As implied above, I provisionally assume that the phonemic contrast was one of lax vs. tense, and additionally suggest that it arose when the first intervocalic clusters including a sibilant, like IE ${ }^{*}-t^{s} t-19$ and ${ }^{*}-t s^{-}$, became /s:/ (to which we may add ${ }^{*}-k s^{-},{ }^{*}-p s->/ s: / 20$ ). The process as a whole may have started in Proto-Italic, since /s/ already had a voiced intervocalic allophone at that stage ${ }^{21}$. Unlike Latin, Oscan had lax sibilants in word-final position, so that, for instance, the suffix of an -s-stem contained a phonemic lax sibilant in every case of the paradigm.

c) The contrast /s/ - /s:/ was neither consistently spelt nor, in all likelihood, existent in all positions from the beginnings of written Oscan (for instance, it was certainly neutralised in initial position). It was mostly rendered $\langle s\rangle$ vs. $\langle s s\rangle$ in the Oscan alphabet, $\langle\zeta\rangle \mid\langle\sigma\rangle$ vs. $\langle\sigma\rangle \mid\langle\sigma \sigma\rangle$ in the Greek alphabet, and $<\mathrm{Z}>$ vs. $<\mathrm{S}>$ in the Latin alphabet.

d) As far as epigraphy in the national alphabet is concerned, the contrast is attested in medial and final position, both intervocalically (cf. fluusaí 'to Flora', Sa 1, Agnone, vs. essuf 'there', Sa 4, Pietrabbondante), in onsets after sonorants (patensíns 'aperirent', Cm 1, Abella, vs. kenssurineís, Cp 24, Capua), in codas (fiísnú 'temple', Cm 1, Abella, vs. kerssnaís 'dinners', Cp 31, Capua; fust 'will be', Cp 31, Capua, vs. ess-kazsiúm 'access', Cm 2, Campania), and in word-final position (as in aasas 'altars', Sa 1, Agnone, vs. feíhúss 'walls', Cm 1, Abella, meddíss 'magistrate' $<*-k-s$, Cm 6, Nola). There are several examples of $<h>$ for final /s/ before wordinitial $\langle s\rangle-$, namely upsatuh sent 'operati sunt' (Si 4, etc., Teanum) and puiieh sum 'cuius sum' (Cp 41, Capua). Final $-<s>$ is also sometimes omitted in the nom. sg. of proper names. This is undoubtedly indicative of lenition ${ }^{22}$.

e) We have few instances of IE intervocalic /s/ in the Greek alphabet, and they show con-

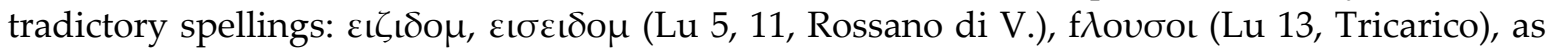
opposed to the gentilic $\kappa \omega \sigma \sigma \alpha \nu \omega$ (IItal. III: 1475-77, Petelia 2), etc. It should be noted that $\langle\zeta\rangle$ is used in medial position (IItal. III: 1485, Caulonia 2, see below 5.4) long before the only text containing it in initial position. The epithet accompanying the dative $\zeta \omega F \eta \iota$ 'Jove' in Lu 35 is $\pi \iota \zeta \eta$ ı. Lejeune (1970: 310) reconstructed a stem *pid-es- «du nom de la source, cf. grec $\pi i ́ \delta \alpha \xi »$, which is most uncompelling ${ }^{23}$. By the same token, one could propose an $-i$-stem action noun

${ }^{19}$ From now on, I shall use this notation for any IE clusters containing a dental sound in immediate contact with / $t$ /, in my view yielding the same outcome.

${ }^{20}$ As in Vestinian OŚIINS (MV 2), with a four-stroked allograph of $<\mathrm{S}>$ reflecting a tense sibilant, $<$ PItal. *op-s'made', and O. OsINS < *op(i)-si-' 'adsint' (Lu 1, Bantia); cf. Rix (1993: 336).

${ }^{21}$ Cf. Untermann (1968), Stuart-Smith (2004: 91). This contrast cannot be equated to that of simple vs. geminate obstruents or sonorants, however. We cannot assert that what I represent as /s:/ actually behaved like a cluster and closed the first syllable in intervocalic position, or that the contrast was one of length rather than, for instance, a combination of other feaures, like aspiration or voice. In some contexts the intervocalic sibilant must have been weakened and dropped earlier. Cf. Weiss (2017); Prósper (2018a) for superlative forms, and now Prósper (2019a) for these and other instances of Venetic and Italian Gaulish * $V z V->{ }^{*}-V \hbar V->-\bar{V}-$.

${ }^{22}$ If this is a valid criterium in order to establish an etymology, it follows that the recently uncovered nestrúis on a tile cannot possibly go back to the comparative corresponding to the superlative nessimas 'next, closest' (as per La Regina 2017). It would have given Sabellic *nessistro-, matching the superlative form *nedzizVmo- > *nessimo-, to judge from SP. meitistrúi, matching the superlative *meitizVmo- > *meitìmo- > meítims 'most gentle, dearest', or the

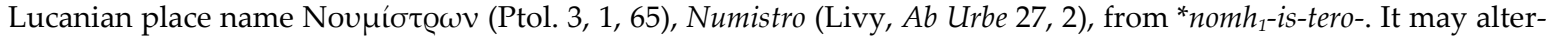
natively be traced to *nes-tero- 'our', L. noster (the root vocalism was modified in analogy to *ues-tero- 'your'), a possibility already considered by WOU: 499. The same probably applies to nistrus (Cp 37, Capua). In MINSTREIS $\left(<{ }^{*}\right.$ ministero- $)$, syncope of both the second and third syllables, which may have operated at different stages, neither compromised the semantics nor gave rise to undesirable phonotactics. Additionally, we have to reckon with analogy, e. g. *mais / *maistro- 'more' vis à vis *mins / *minstro- 'less', so the processes involved are not entirely clear.

${ }^{23}$ The rest of the hypotheses about this name presuppose errors in the anlaut or declensional type and can be outright rejected (see WOU: 562). 
${ }^{*} k^{u}$ eis-i-, * $k^{u} i s-e i-$ 'survey' (from ${ }^{*} k^{u}$ eis- 'auf etw. achten, wahrnehmen', LIV: 381) which eventually became an agent noun, and relate this formula to Iuppiter Quirinus (<* $\left.k^{*} i s i-h_{1} n-o-\right)$ or even to the Quirites, a name that designated the citizens of Rome in peacetime duties, when they were seeing to their own or public business corresponding to their capacities (if one is allowed to reconstruct * $k$ u isi-i-t- 'survey-goer'; the multifarious, often untenable associations put forward for this name since ancient times lie beyond the scope of this work). In that case, $\langle>\rangle$ would stand for /ẹ/, as is sometimes the case.

The Greek alphabet reflects no contrast in codas any longer, since the phoneme distribution was by that time contingent on the voice specification of the following consonant, as in $\alpha \mathrm{l} \zeta v i \omega$

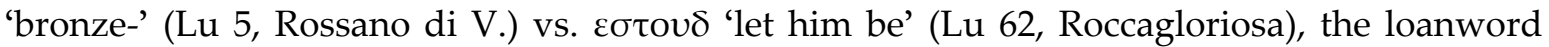
$\kappa \mathrm{F} \alpha \iota \sigma \tau \mathrm{\imath}$ ( $\mathrm{Lu} 6,7$, Rossano di V.), and we no longer find the double spelling $\langle\sigma \sigma\rangle$ in any case.

The contrast between a voiced and a voiceless sibilant emerges in initial position only after *di- has been fricativised, as transpires from one single case in the Greek alphabet, the dative $\zeta \omega F \eta \iota$ 'to Jove' ( $\mathrm{Lu} 35$, Rossano di V., around $200 \mathrm{BC}$ ). By contrast, this name is rendered diúveí (Sa 1, Agnone) or iúveí (Cm 9, Cumae) in the national alphabet. As regards phonetics, all the synchronic contrasts are now likely to translate into [z] vs. [s] in onsets, that is to say in initial position and word-medially. This is suggestive of a reorganisation of the phonemic contrast, which has been abandoned in coda position but has arisen in word-initial position, where it was previously non-existent. I am agnostic as to whether this is a dialectal (cf. Zair 2016: 110-112) or a chronological problem, or both ${ }^{24}$.

f) We find exactly the same distinction in the Latin alphabet, but it is much more systematically spelt: cf. ZICOLOM vs. SVAE, CENSAZET vs. ESVF (Lu 1, Bantia), though in the Oscan dialects it is ignored in favour of a cover-symbol $\langle\mathrm{S}\rangle$, as in Paelignian and Marrucinian. There is no trace of the double spelling anymore, in spite of the same document containing $\langle\mathrm{LL}\rangle,\langle\mathrm{DD}\rangle$, and in codas the contrast has been given up wholesale, as in MINSTREIS (cf. L. minister), MEDDIS, etc. It cannot be put down to chance that both the Greek and the Latin alphabet have chosen these letters for the same contrast ${ }^{25}$. A subphonemic spelling system would be comparatively anomalous, but in this case we would find no fewer than two; this is hardly conceivable when it comes to the use of the Latin alphabet, in which $<Z>$ played a very minor role. It follows from the abovesaid that the Greek and Latin alphabets are noting a phonemic contrast that is no longer one of tenseness, but of voice.

g) All this has some bearing on the problem of why Oscan borrowings from Greek or Latin show a geminate in unexpected slots, specifically in the sequence <sst>: cf. kvaisstur (Po 3, 4, Pompei), perisstyl[eís (Cm 1, Abella), passtata (Po 5, Pompei), as opposed to the wellintegrated Latin loanword trístamentud (Po 3, Pompei), etc. Zair (2016: 163-164) notes that «the spelling of this sequence as <sst> is restricted to loan-words from Latin and Greek», and that «there is evidence of gemination (or ambisyllabicity) of /s/ before / $\mathrm{t} /$ in both Greek and Latin» (fn. 27); he further observes that «we do not find $\langle\sigma \sigma\rangle$ in these environments in the Greek in-

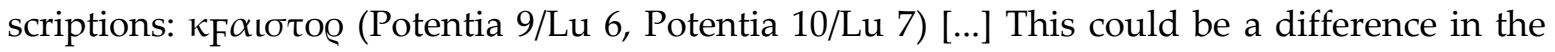
orthography of double letters between the Oscan and Greek alphabets ([sst] in borrowed words treated as any other geminate in the Greek alphabet, while being nearly always written in the Oscan alphabet)».

${ }^{24}$ Concerning the date of the adoption of writing rather than that of the individual inscriptions, which in the case of the national alphabet can be situated in the second half of the $5^{\text {th }} \mathrm{C}$. BC at the latest.

25 This is timidly conceded by Stuart-Smith (2004: 91, fn. 111): «This convention may have arisen because [z] from /-s-/ became identified with $/ z /\left(<{ }^{*} d y\right.$-), which was represented with $\langle\zeta\rangle$ ». Sometimes, this is described as the intervocalic allophone [z] of /s/ (cf. Zair 2016: 105-109; 129-130), which is contradictory, given the obvious contrast in initial position. 
In my view, the use of $\langle\sigma\rangle$ in borrowings attested in Oscan in the Greek alphabet is simply reflecting neutralisation of sibilants in coda position. By contrast, $<s s>$ in the Oscan alphabet is not noting a geminate proper, but a tense sibilant that was still phonemic in that context at that time and place. $<s s t>$ cannot have been restricted to loanwords, even if no vernacular sequence [s:t] is attested ([s:k] in esskazsíum is strictly equivalent, however). In fact, speakers of languages possessing the phonemic contrast /s/ - /s:/ in intervocalic position, like Greek or Latin, tend to maximise it not only by lengthening the articulation of /s:/, but also by shortening /s/ as much as possible. In coda position, however, where it is usually non-contrastive, /s/ tends to have an allophonically longer duration, and preconsonantal resistance to aspiration is then greater. This may be the ultimate reason for the sporadic writing $\langle\sigma \sigma \tau\rangle,\langle\sigma \sigma \kappa\rangle$, etc. in Greek epigraphy: it is not likely to reflect the ambisyllabicity of $/ \mathrm{s} /$, as occasionally suggested, but is more plausibly related to the longer phonetic duration of /s/ in codas, which made it phonemically ambiguous for the speakers ${ }^{26}$.

Conversely, as observed above, Oscan had a weak sibilant/s/ which came to stand in contrast with /s:/, the product of the simplification of some preconsonantal clusters, both in intervocalic and in coda position. As a consequence, Latin or Greek sibilants, which were usually realised as tense in codas, were identified by the Oscans with their own tense phoneme, and systematically rendered <ss> in the national alphabet. In Oscan in the Greek alphabet, as we have seen, the contrast was often expressed by $\langle\zeta\rangle$ vs. $\langle\sigma\rangle$ but had been neutralised in codas, where their use is contingent upon the voice specification of the following segment. As a consequence, we do not a priori expect to find $\langle\sigma \sigma \tau\rangle,\langle\sigma \sigma \kappa\rangle$, etc., whether in patrimonial forms or in loanwords from Greek (unless, of course, one could prove that blind imitation of Greek written models exhibiting this particular anomaly was at play).

\section{The Indo-European sequences ${ }^{*}-n s-,{ }^{*}-n s \#$ and ${ }^{*}-n t^{s} t$ - in Italic}

The changes associated to the unstable cluster /ns/ in Italic are far from well known. Contrary to common belief, the phonotactic side is not irrelevant, and it is necessary to distinguish carefully between the prevocalic and preconsonantal outcome.

5.1. The IE sequence ${ }^{*}-V n . s V$ - may have passed to $-\bar{V} s V$ - in all the dialects, possibly at an early date. In fact, loss of the heterosyllabic nasal segment in this context is a widespread phenomenon in the Indo-European family: it is a very early change in Celtic, and occurred in several Germanic branches (specifically Anglo-Frisian and Scandinavian) and Balto-Slavic. The poverty of reliable information coming from Sabellic stops us from venturing any far-reaching assumptions. While some scholars (notably Buck 1904: 72) have proposed an early Sabellic evolution $-V n s->-V n^{t} s-$ on the strength of forms like U. menzne, uze, O. keenzstur, kenzsur, these are unreliable pieces of evidence: the whole lexical family of the Oscan form is now considered to be a borrowing from L. cênsor (WOU: 382-386). On the Umbrian forms see below 5.4. Since the forms containing this inherited sequence are comparatively few, it may have been the case that the resulting intervocalic sibilant in $-\bar{V}_{S} V$ - was phonemicised as a tense/voiceless sibilant, which possibly merged in Sabellic with the one going back to geminates and clusters. In other words, loss of the nasal segment, however early, necessarily followed Proto-Italic voicing of intervocalic /s/, and consequently stands in a counterfeeding relation to it. IE /s/ never became voiced by the action of a preceding nasal, and the cross-linguistic generalisation obtains that

\footnotetext{
${ }^{26}$ See Méndez Dosuna (1996) for these typological considerations and their application to the Greek case.
} 
fricatives, as opposed to stops, usually fail to undergo voicing after nasals ${ }^{27}$. Let us now examine our extant evidence:

U. iseçeles (abl. pl. fem., Um 1 IV 7, held to stand for correct tiseçetes) is said to go back to a past part. *en-sek-eto- 'cut' with loss of /n/ and lengthening of /e/ across morpheme boundaries. It is immediately preceded by aseçetes (abl. pl. fem., Um 1 IV 7), and earlier by aseçeta (abl. sg. fem., Um 1 IIa 29), in turn possibly from a very similar compound *an-sek-eto- 'not yet cut'. This could point to early loss of the identity of the preverbs, which would indicate that $-V n s V$ generally gave $-\bar{V} s V$ - in Umbrian. Couples like snata vs. asnata (Um 1 IIa 19), which are equally held to contain the same privative prefix an- but systematically omit the nasal in writing, are also likely to have undergone early nasal loss and probably lengthening even when the sibilant preceded another consonant, at least across a morpheme boundary (see below 5.4 for Sabellic $\left.-n \# s->-n^{t} s-\right)$. We have no information about the evolution of ${ }^{*}-V n s V$ - in Oscan ${ }^{28}$.

The arguably early date of this phenomenon as a whole is seemingly belied by the regularity of the Latin notation of $/ \mathrm{n} /$ in its original loci. The first attestation of forms without the nasal is the epitaph of Scipio Barbatus' son (CIL I': 8, 9; $3^{\text {rd }}$ C. BC, Rome), where we find CESOR and cosol (borrowed in Oscan as kúsúl, Po 54, Pompei, cf. Poccetti 2006). Relative chronology is of little help here. In point of fact, a number of examples have been invoked in favour of the idea that the change deleting nasals before fricatives was not early, since it was preceded by vowel reduction in closed syllables and raising of -enK-, in turn later than vowel reduction (see Weiss 2009: 120). But the validity of the first obstacle is contingent upon the chosen etymology (if anhēlus is from *anaslo-, not *an-anslo-, the problem vanishes) ${ }^{29}$.

Let us suppose that $/ \mathrm{n} /$ had been effaced in this context before the creation of the Latin alphabet, but later than the Proto-Italic voicing * $V s V->-V z V-$. As regards etymological *-Vn.s $V-$, it would be feasible to recover the lost nasal segment (even if the preceding vowel had already been denasalised, which is debatable), from synchronic morphophonemic alternations, id est from sequences going back to ${ }^{*}-n t^{s} t$-, which may have been simplified and lost the nasal in Latin some time later, but possibly before or around the time at which the alphabetic writing was adopted. In these sequences, the existence of an underlying nasal was recoverable in view of such morphophonemic alternations as fendō-fēnsus, in which according to this hypothesis the nasal had been effaced in the past participle. In imitation of these cases, which were comparatively frequent, such forms containing the inherited heterosyllabic sequence * $n$.sas ānsa [a:sa:] 'grip', ènsis [e:sis] 'sword' could be rightly interpreted as underlying /ansa:/, /ensis/ and were accorded a distinctive spelling which prevented confusion and promoted orthographic uniformity, and vowel length in a sequence $-\bar{V}_{s}$ - was correctly parsed as derived from the underlying nasal (it should be clear by now that, at any rate, the upper or cultivated classes might have preserved vowel nasalisation longer). By that time, intervocalic sibilants had been voiced and progressively weakened into an approximant, as in /a:sa:/ [a:ża:] 'al-

${ }^{27}$ According to one theory (Vaux 1998), voiceless fricatives are specified as [+spread] and voiced fricatives are specified as [-spread]. Since the feature combination [+nasal][+spread] is not allowed, nasals cannot spread voicing to a fricative.

${ }^{28}$ Poccetti (2016: 357) argues that -ns- is generally preserved in Oscan, but none of his examples reflects etymological -ns-: patensins is the product of samprasarana, censaum is a loanword, and $\phi \varepsilon v \sigma \varepsilon Q / f e n s e r n u m$ on coins $(\mathrm{nCm} 6 \mathrm{a}, \mathrm{b})$ goes back either to a *- $t V$ - derivative of ${ }^{*} g^{u h} e n-d^{h}\left(h_{1}\right)$ - 'attack, kill' or to * $d^{h} e h_{1} n e s-$ 'yield', as in L. fēnus 'interest'.

${ }^{29}$ As for the second, Weiss (fn. 19) invokes * $k^{u} e n k^{u}-n o i>{ }^{*} k^{u}-I n x-n o i>q u \bar{\imath} n \bar{\imath}$ 'five at a time'. But, beside the fact that these two changes are in principle independent, vowel raising between two velar sounds must be quite early since the best term of comparison is ${ }^{*} k e n k$-to- $>$ L. cinctus, U. šihitu. I would then start from ${ }^{*} k^{4} I \eta x-t o-/ n o->{ }^{*} k \bar{\imath}(x)$ tos $\gg$ quīntus, ${ }^{*} k \bar{\imath}(x)$ noi $>$ quīnī vs. a cardinal ${ }^{*} k^{u} 0 \eta k^{u} e$. 
tar' > āra (where the underlying /s/ could be positively recovered from alternations like *flōs, flōz-es) ${ }^{30}$.

In short, Latin might have used morphophonemic writing from the beginning, a wellknown means of keeping the visual uniformity of the paradigm. Once the spelling of the main allomorph, in this case the one synchronically preserving the nasal, as in fendō, condō, was chosen and assigned to the morphologically derived forms like the past participles and the action nouns, the spelling $<$ NS $>$ naturally spread to the rendition of forms that showed identical phonetics but lacked the requisite inner-paradigmatic alternations. The «correct» usage in forms which were not individually subject to these alternations fell out from this practice straightforwardly: in fact they were a minority, and they could often be parsed as past participles, as in ānsa, dènsus, or nominal derivatives, as in mènsis, as well as the origonyms in -ênsis, which may have contained ${ }^{*}-t^{s} t$-. The erstwhile existence of a nasal could be additionally retrieved in compounds like cōnsol, cōnsulere, which would definitely have favoured morphological spelling. On the other hand, the overgeneralisation of the pattern to forms without alternations of either origin would have had a distortion effect if there had been more than one source for these forms. In other words, if there had been any other IE sequence giving $-\bar{V} s$ - in nonalternating contexts, hypercorrection leading to insertion of $\langle n\rangle$ would probably have occurred. This implies that degemination in the context $-\bar{V} s_{s-}^{-}$, as in cāsus, causa, took place posterior to the emergence of Latin orthographic conventions, and that at that time there were contrasting pairs like /ansa:/ 'handgrip', /a:sa:/ 'altar', /a:s:a:/ 'burnt'.

Later on, the distinctions were largely obscured by rhotacism, geminates were simplified after long vowels, and for most speakers, especially when they were illiterate, $\bar{a} n s a$ and $\bar{a} s a$ 'burnt' were simply homonymous, and there was no reason to accord them a different phonemic status anymore. Consequently, spellings like FORMONSVS constitute the late, hypercorrect side effect of this merger. Only the literate, educated individuals persisted in the distinction and even made a point of pronouncing the nasal as a token of high status and distinction. More crudely put, the pronunciation of a nasal in this context is entirely artificial and based on the psychological tendency to establish a biunivocal one-to-one correspondence between alphabetic signs and phonemes that makes Latin orthography so easy and English orthography so tricky to learn. Classical testimonies about the alternation of the realisations [V:s], [V:ns] or [Vns] simply reflect the perplexity of the upper literate classes, who had nothing close to the modern notion of diachrony, but suspected that what was in fact only spelling pronunciation must have been more «correct» or elevated than everyday usage. Specifically, the occasionally reported realisation [V:ns] introduces the effect of nasal loss without nasal loss, because it unduly conflates written and spoken word, and testifies to the distance between spelling and phonetics ${ }^{31}$.

30 To judge from cases like L. cēnseō $<{ }^{*} k_{n} s_{-}-e h_{1^{-}}$, this change presupposes [n] $>$[æn], which in turn must have been quite early. One could, for instance, object that a two-stage evolution [n] $>$ [an] $>$ [æn] is more plausible and brings Latin into line with Venetic and Sabellic. But then, forms like grandis, scandō or sanciō must have missed the last shift for some reason. At any rate, forms like inscēnsiō are likely to be the product of an analogical proportion on the present indicative, in this case inscendō (vis à vis scandō; scānsus) and not the direct outcome of *-skanssothrough reduction [a] $>$ [e] followed by loss of $/ \mathrm{n} /$.

${ }^{31}$ When Cicero reports in his Orator a pronunciation in-doctus but in-sanus he is accordingly testifying to the morphological restoration of the nasal in compounds, not to its preservation, since he fails to eliminate the vowel length resulting from nasal effacement. That he (or the high class as a whole) opted for partial restoration of the prefix (undoubtedly aided by the ironclad stability of the Roman orthography) is immaterial to the fact that he was said to pronounce foresia, hortesia, Megalesia by Velius Longus (incidentally, -ēnsis is probably the best example of a non-lexical intramorphemic cluster [V:s], and the only one in which omission of $<\mathrm{N}>$ was by that time widely tolerated in writing). The isolated Latin sequences MENSSES (Rome), COMITATENSSI (Picenum, $4^{\text {th }}$ C. AD) are most 
If, as I contend, the designers of the earliest Latin writing system felt it was convenient to introduce nasals for the sake of homogeneity and economy in places in which they were being progressively given up or no longer actually realised by at least lower social layers, their decision amounted to deduction. In spite of much of current scholarship, it is idle to invoke the authority of Greek or Oscan borrowings: they are often taken from the written language, and are accordingly as likely to be diagnostic of the preservation of the nasal segment at that time as contemporary Sp. defensa, cónsul or infierno to bear witness to the Latin pronunciation of, possibly, any period after the writing tradition set in ${ }^{32}$. The fact that the effects of nasal loss and the ensuing compensatory lengthening surface in the Romance languages transparenly cannot mislead us into thinking that Late Latin is the only conceivable terminus ante quem, and that, as universally assumed, this must be a comparatively late phenomenon.

Only in absolute final position (or, more generally, in complex codas) was the original nasal segment impossible to restore in Latin, as in the acc. pl. ending ${ }^{*}$-ons $>-\bar{o}$ s, since the outcome of $-\bar{V} s$ was identical. In these endings, the resulting form eventually merged with nasalless forms, e. g., the fem. sg. $-\bar{a} s$, in contrast to such proclitics and prefixes as trāns, which often appear preceding a vowel, and in such cases of final vowel syncope as mōns, montis or present participles in $-\bar{e} n s$, where it was also restored in writing for morphophonemic reasons.

To recap, the shift * $V n . s V->-\bar{V} . s V$ - is likely to be shared by all the Italic languages, even if it may have been an independent process taking place at different dates and language stages, and we can at most vaguely speak of a Common-Italic tendency. The change may have been gradual and socially stratified, and the date(s) in which nasal effacement was completed cannot be ascertained, but in any event it may have preceded the period of our earliest documents.

\section{2. * ${ }^{*} s(-),{ }^{*}-n s(-)$ in coda position including auslaut}

5.2.1. The sequence -Vns.C- becomes $-V s s C$ - in Oscan, -VfC- in South-Picene and probably Umbrian, and $-V / \bar{V}_{s} C$ - in Latin and probably Venetic (note that in the extant examples the cluster is additionally intramorphemic).

L. mōnstruum and SP. múfqlúm 'monument' are habitually traced to *mones-tr/lo- (Marinetti 1985: 118, 127; cf. WOU: 480), but Vine's alternative reconstruction *mons-tlo- (1993: 127-130) is more compelling (since, to begin with, post-syncope -ns- would not be certain to yield $-f$ - in South-Picene). The erstwhile existence of a nasal segment could be deduced in mōnstrum from the verb moneō, but was ignored in the less transparent mōstellāria, as in mēnstruum vs. trimēstris. But the regular, inherited forms could have been *mŏstrom and *mĕstruom. In that case, mostellaria and semmestris would not only have regularly lost the nasal segment, but would additionally have contained short vowels all along.

As for SP. múfqlúm, the first vowel is reflective of raising of /o/ before the nasal, and the vowel may consequently never have been long ${ }^{33}$. Interestingly, if we assume a homogeneous behaviour of nasal + fricative clusters in codas, this is suggestive of compensatory lengthening

unlikely to be rendering a non-existent phonetic sequence [ns:]. they reflect a compromise solution between orthography and the usual hesitation $[\mathrm{V}: \mathrm{C}] /[\mathrm{VCC}]$, usually termed «Iuppiter-» or «flamma»-rule, which has given rise to the uncommon spelling MESSES (Transpadana, Britannia, Proconsularis). Poccetti (2006) believes all the variants to be somehow phonetic, which I deem very unlikely. See Adams (2013: 178-182) for the opinions of the ancient grammarians on this matter.

${ }^{32}$ In spite of this, most educated native speakers would swear these forms are patrimonial and have always contained [n], and handbooks often misleadingly speak of «preservation» of the nasal in learned words.

$33<\dot{u} m>$ and $<0 m>$ then reflect the respective outcomes of IE *-om\# and *-ōm\#. According to Weiss (1998), the former has been raised to -ọm\# $(-<\dot{u} m>)$ before the latter was shortened and lowered into -om\# $(-<0 m>)$. 
in the Proto-Italic sequences ${ }^{*}-n x . n$ - and ${ }^{*}-n x$.t- having taken place only after the progressively lenited (post-)velar sound had become debuccalised into $/ \mathrm{h} /{ }^{34}$.

It follows that $\langle\omega\rangle$ stands for $/ \mathrm{o} /$ in O. $\kappa \omega \sigma(\tau) \iota \tau$ (?3 $3^{\text {rd }}$ pers. pl., Lu 5, Rossano di V.), to judge from examples like $\pi \omega \mu \pi$ ovı $\varsigma$ (in the same document), or the acc. sg. ending $-\omega \mu$. The nasal segment was trivially omitted in writing but probably never lost in a transparent compound *kom-st-. Consequently, eestint ( $3^{\text {rd }}$ pers. pl., Sa 1, B1, Agnone), if from *en-st-, would be the only case of lengthening in codas after nasal loss. In fact, as often remarked, it is more likely to continue the Sabellic prefix $\bar{e}$ - from ${ }^{*} e k$ - attested as O. eh-, U. ehe- (Meiser 1986: 167) and eestint can then be translated as 'exist', or possibly 'outstand, be remarkable'.

Conversely, O. esskazsíum 'disembarkation (point)' (Cm 2, Campania), which WOU: 235, in the footsteps of Mario Russo, compares to L. éscènsiō and traces back to *esskanssẹom (<*eksskand-tei-o-), is much more likely to go back to *en-skand-tei-o-, a full match of L. inscēnsiō 'embarking'. This noun may have had a specialised meaning 'embarkment place'; alternatively, it simply designated the staircase access that ran upwards from the sea to the temple of Minerva. As observed above, an ablative prefix would be expected to give ${ }^{*} \bar{e}_{-}$, and the attested form would have been teeskazsíum.

5.2.2. The word-final sequence ${ }^{*}$-ns\#, attested only in the accusative plural endings, shows the same outcomes in Sabellic as in coda position, and a preceding short vowel regularly undergoes syncope in athematic inflections

In the consonant stems, *-ns \# is attested in O. usurs '?', fakinss 'actions', aginss 'actions, rituals', U. CAPIF 'offering tray' (<*kapid-ngs), frif 'fruits' (< ${ }^{*}$ frūg-nns), U., SP. nerf '(noble)men' $(<* n e r-n s$, respectively Um 1 VIa and SP TE 6, Penna Sta. Andrea).

In the -i-stems, the acc. pl. *-i-ns\# surfaces in Umbrian as AVIF, AVEIF, AVEF, which reflects - ef (without compensatory lengthening), and not -if (from *if or ${ }^{*}-\bar{i} s$ ). Restoration of the stem vowel $-i$ - may have been favoured by the undesirability of an outcome *au $f>{ }^{*} \bar{o} f$, however. In SEVACNE(F) 'sollemn', vowel loss would have resulted in samprasarana, creating a skewed paradigm. In turn, TREIF/tref 'three', straightforwardly renders /trẹf/ (from *trins) and may have partly served as the model for the other forms (and one does not see why it should have been refashioned from earlier, allegedly regular ${ }^{*}$ trîf or ${ }^{*}$ trīs).

There is additionally no reason to believe that U. manf 'hands' is not a $-u$ - stem like the abl. sg. mani or the loc. sg. manuve, and in that case it must have undergone regular syncope without subsequent restoration of the stem vowel, since, in contrast to the above - $i$-stem examples, it caused no real disturbance to either the uniformity or transparency of the para$\operatorname{digm}^{35}$.

The Oscan thematic acc. pl. forms feíhúss and bravús[s] (Cm 1, Abella) are hardly diagnostic, since for probably dialectal reasons peculiar to Samnium and some parts of Campania, these forms show a short vowel /o/ in line with the rest of the endings in which a long vowel would be expected, like abl. sg. -úd, nom. pl. -ús. By contrast, Umbrian shows $\langle u\rangle \mid\langle v\rangle$, which points to /o:/ > /u:/ (turuf/TORV). Consequently, the synchronic endings are O. -oss/-ūss, U. $-\bar{u} f$. In my present view, these forms have reinserted the thematic vowel by analogy with the

${ }^{34}$ This is fully compatible with the idea that this segment has undergone $j$-prevocalisation in Venetic, see Prósper (2018b).

${ }^{35}$ In spite of virtually all previous scholarship, summarised by WOU 450. Klingenschmitt (1992) simply ignores the obvious solution when he states that this acc. pl. has been remodeled on that of *ped- $f$ 'feet', for which there is no reason whatsoever. For the stem *manu- in Oscan manim and a new reading $\mu \alpha v o[v \mu]$ of Lu 62, B7, Roccagloriosa, cf. now Zair (2016: 207). On the origins of *manu-, cf. Neri (2012: 185, fn. 6). 
nom. pl. ${ }^{*}-\bar{o} s$ after final vowel syncope, since all the plural forms contained a thematic vowel $-\breve{o} / \bar{o}-$. For all we know, this may have happened independently in the two branches of Sabellic.

If the feminine correlate of ${ }^{*}$-ons was Proto-Italic ${ }^{*}-\bar{a} s$, and not ${ }^{*}-\bar{a} n s$, with Indo-European loss of the nasal, the attested Sabellic endings, O. -āss (víass, ekass), U. - $\bar{a} f$ (vitlaf, eaf), must have come into being by analogy with the masculine. By contrast, the South-Picene acc. pl. fem. ending -as in qoras 'stone monument (vel sim.)' (Sp TE 7, Penna Sta. Andrea), otherwise identical to O. kúrass (Sa 10, Pietrabbondante) may be the only Sabellic ending to continue the inherited *ās unchanged.

Latin shows $-\bar{V} s$ in all the inflections: cf. L. eās, deōs, patrēs. Venetic is ambiguous: our best example thus far is te.r.mon.io.s de.i.vo.s. 'deos terminales' ( $L V: 125$, Vicenza). But one early example reads donal.s.to .a.i.su.ś 'donavit deos' ( $L V: 243$, Gurina), where the acc. pl. still shows the symbol $\langle\dot{s}\rangle$ for the tense sibilant that later fell into disuse, probably because of the progressive weakening and eventual effacement of the lax sibilant in a number of contexts. This leads me to suspect that Venetic may have teamed up with Oscan in this respect, and that ${ }^{*}$-ns\# > ${ }^{*}-n^{t}$ s\# may have been an areal feature covering Sabellic and Venetic (cf. Prósper 2018a for the similar northward expansion of other innovations).

To recap, Proto-Sabellic *-ens, ${ }^{*}$-ins and *-uns regularly lost their stem vowel by syncope somewhere down the line. The undesired grammatical consequences of this change were counteracted by partial restoration of the stem vowel where needed. Contrary to one widespread idea, it is illogical to take syncopation to have exclusively happened in the consonant stems, in which *-ens goes back to *ns. If the nasal remained vocalic long enough, it could even have escaped syncope ${ }^{36}$. There is also every reason to cast doubts on the assumption that compensatory lengthening must have taken place, and that the allegedly Proto-Italic thematic ending $-\bar{o} f /-\bar{o} s$ is regular and the rest of the stems, failing to show the expected outcome $-\bar{e} f,-\bar{\imath} f$ and $-\bar{u} f$, are the product of analogical processes.

\subsubsection{A phonetic explanation}

The divergent outcomes of -ns in coda position have never been properly accounted for beyond mere description. This has always included a number of versions of an unwarranted shift $-s>-\theta$, which for some reason only took place when a nasal or rhotic immediately preceded the sibilant. In point of fact, in the world's languages it is usually the nasal that adapts its articulation to the following obstruent. This is the norm with stops but not with fricatives, however, the resulting clusters often remaining non-homorganic (see Repetti 2002). Accordingly, it is unlikely that the whole process was set in motion only because the apico-alveolar sibilant had spontaneously advanced its place of articulation to the point of becoming [ $\theta]$, and exclusively in this particular context.

In my view, the first stage, common to all the Sabellic languages, can be described as blocking of the difficult nasal-fricative transition by an epenthetic homorganic stop, a phenomenon attested in Hittite, Tocharian, Basque, a sizable number of Italian dialects, a number of Modern Greek dialects, optional realisations of British English words, like mince [min(t)s], and most American English dialects. It is due to mistiming in the coordination of several articulators: see Ohala (1997), Warner et al. (2001). The velum is raised before the oral cavity is opened and the air is released. This suggests, firstly, that the Sabellic outcome of -Vns\# reflects

${ }^{36}$ This would make the actual outcome ipso facto analogical, a path tentatively followed by Rix (1986: 584585) which I find rather speculative, and that he later on (588) replaced by an allegedly regular, Ursabellisches ending $-(e) f$. 
the preconsonantal sandhi variant, and that it has undergone excrescence of a subphonemic homorganic dentoalveolar stop and became $-n^{t} s^{37}$. It should be noted that, while the excrescence of a homorganic stop to block the nasal-fricative transition generates highly marked codas, some dialects, notably American English, only show this phenomenon in coda position (as in false vs. falsity). Thereupon, the nasal segment was lost, probably leaving a trace in the nasalisation of the preceding vowel, and -ts became phonemic. This was possible because there were no morphophonemic alternations that allowed the speaker to recover the underlying - ns, and perhaps also because the epenthetic stop was no longer linked to the presence of a nasal in the speaker's conscience, though this is not strictly necessary: as we are going to see, the intervocalic sequence - ns- no longer existed and - ntss- had an underlying stop and evolved in Sabellic in exactly the same direction as $-n^{t} s^{38}$.

Thereupon, -ts was weakened to a fricative. In turn, this was probably favoured by the comparatively high tendency of coronal sounds to assimilate to following sounds. In Oscan, the resulting sound merged with the tense sibilant $(>-s s)$. In Umbrian and South-Picene, the new sibilant * $(V)$ s preserved its dentoalveolar articulation, subsequently became an interdental voiceless fricative ${ }^{*}-(V) \theta^{39}$, and eventually merged with /f/ by acoustic similarity, since these sounds are easily confusable. In both cases, the difference with original $-V / \bar{V} s$ was preserved, and consequently syncretism of the acc. pl. with the nom. pl. never took place. In fact, this is an inescapable conclusion given the similar, earlier change involving an inherited sequence * $n$ ts\#, which became ${ }^{*}-(n) \theta \#$ and eventually $-f \#$ in all the Sabellic dialects in the nom. sg. of $-n t$-stems.

The course followed by Umbrian is reminiscent of the change $-t i->-t s->-s_{n}->-\theta$ - that took place in Spanish in the $16^{\text {th }} \mathrm{C}$. AD (cf. martio > março > marzo; sperantia > esperança $>$ esperanza), and was probably due to the need of maximising the contrast between sibilants: the dental voiceless /s/, the apicoalveolar voiceless /s/ and the palatoalveolar voiceless / $/$ /. By contrast, the Spanish variety spoken in America and vast areas of southern Spain simply abandoned the (cross-linguistically infrequent) phonemic contrast between the inherited /s/ and /s/, which are usually realised as a dental sibilant [s]. The phoneme / $/$ / is also known to have existed (at least after syncope eliminated the phonetic conditioning) in Umbrian and South-Picene, whose national alphabets have a special symbol for $/ \int /$, but did not exist, or not so early, in Oscan. This suggests that Umbrian already had /s/ in its phonemic inventory by the time it became $/ \theta /$ because the threefold contrast tended to be maximised and eventually merged with /f/, reducing the number of phonemic contrasts. In Oscan, our sibilant was smoothly integrated in the system and simply fed the preexistent contrast/s:/ - /s/.

Consequently, this goes some steps towards explaining the limited distribution of the change $[\mathrm{ts}]>[\mathrm{s}]>[\theta]>[\mathrm{f}]$ in Italic. It is difficult to say whether there was a last common Sabellic phonetic stage before final vowel syncope $\left(-n^{t} s\right.$ never merged with post-syncope -ts anyway) or whether syncope affected two already differentiated sequences, e. g. O. $-V s s$ and $\mathrm{U} .{ }^{*}-V_{\mathrm{n}}{ }^{*}-V \theta$.

5.2.4. A different question is whether compensatory lengthening is expected after loss of the nasal segment, and then, which inflections show analogical leveling. In my view, compensatory lengthening is a priori not expected in codas, since the nasality was reassigned to the

${ }^{37}$ From now on, the symbol $\langle t>$ will be used to note the product of the rule by which a subphonemic [t] is optionally inserted, and not a specific phonetic content; accordingly, it will not be used inside square brackets (cf. on this notational problem Akamatsu 2011).

${ }^{38}$ While the subphonemic status of the epenthetic stop raises some questions, Akamatsu (2011) has argued that $[n t]$, in which $[t]$ is epenthetic, is an allophone of $/ n /$.

${ }^{39}$ By neutralisation of stridency as per Hamp (1972), who introduces this step to account for the Proto-Italic shift (-)sr-> (-) $\theta / \partial r->(-) f / \beta r-$. 
vowel and the nasal segment may have disappeared before the excrescent stop became phonemic and the resulting -ts underwent weakening. As claimed above, the Sabellic evolution, in order to be credible, must be envisioned as a many stage process ${ }^{*}-n s>^{*}-n^{t} S>^{*}-s>^{*}-\theta /-s S>-f /-s S$, whose second stage would actually have prevented lengthening.

In the last years, a number of approaches have pointed to a perceptual basis for compensatory lengthening. According to Ohala et al. (1995), the margins of vowels preceding fricatives have an acoustic effect that mimics nasalisation. If there is a nasal segment, listeners could regard it as illusory and discount it. Along the same lines, Kavitskaya (2002: 58-60) has further argued that nasal deletion before fricatives triggers lengthening «since nasalized vowels are phonetically longer than oral ones and thus can be reinterpreted as long with loss of the nasal.» She, however, adds that some exceptions shown by a number of Greek dialects (Cyrenean, Thessalian, Arcadian) which have an acc. pl. form in -ŏs, fail to show lengthening because, in her own words, «word-final syllables stay closed regardless of the n-loss. Thus, it can be argued that, even if nasalized vowels in the last syllable in the word are as long phonetically as nasalized vowels word-medially, they do not necessarily get reanalyzed as long» ${ }^{40}$. The same loss, without consequences for the length of the vowel, which is only expected if the language already possesses a length contrast in the vowel system, is also reported to be occurring in contemporary Romance languages: see Recasens (2018: 165) for dialectal Catalan tens 'you have' > tes, etc.

\subsection{Indo-European ${ }^{*}-n t^{s} t$ - in Sabellic}

The outcome of ${ }^{*} n t^{s} t$ - merged with the outcome of intervocalic ${ }^{*} n s-$ in Latin, but yielded Oscan -ntss-, Umbrian - $f-$, and Venetic -nss-.

In Oscan, this transpires from the context-bound use of $<z s>$ in esskazsíum [es:kants:iom] and in kenzsur 'censor'. Oscan borrowed the family of kenzsur, keenzstur (redone as *kens-tōr-), etc. from the Latin written language and interpreted the cluster at face value: it must have sounded similar to their own agent nouns and past participles built from roots ending up in a dentoalveolar sound. In other words, the Oscan scribes overestimated the phonetic reality of the Latin spelling $<\mathrm{NS}>41$. In such forms as húrz 'garden' $\left({ }^{*}{ }^{*} g^{h}\right.$ ortos), $<z>$ is rendering an affricate phoneme /ts/. Accordingly, the Oscan tense sibilant /s:/ had a post-nasal variant [ts:] which was spelt $\langle s s>$ in kenssurineís, but may have been more or less regularly spelt $\langle z s\rangle$. As for Umbrian, * $n t^{s} t$ - yielded -f- with nasal loss: cf. mefa (if identical to L. mēnsa), possibly SPEFA, the form that follows it in some passages (in Um $1 \mathrm{VIa} / \mathrm{b}, \mathrm{VIIa}$ ), and spafu (if < ${ }^{*}$ spnod-to-, Va 20) ${ }^{42}$. Compensatory lengthening cannot be ascertained.

All this points to the existence of a common Sabellic stage $-V n$.tss $V-$, which apparently remained unchanged in Oscan, but underwent the expected changes into ${ }^{*}-\tilde{V}_{n}->^{*}-V / \tilde{V} \theta->-V f$ - in Umbrian. The reasons for positing an underlying, not excrescent homorganic dentoalveolar sound in this context will become clear at the end of this work. This contrasts with the panItalic evolution *-VtstV->-VssV-: cf. U. FISO (divine name, Um $1 \mathrm{VIb},<{ }^{*} b^{h} i d^{h}$-to-), and also *-ts-,

${ }^{40}$ See also Alonso-Déniz (2011) for nasal loss without lengthening in the Greek sequence *-VnsC-, which he puts down to the fact that the mora count stays stable after nasal loss. This means that, even if the nasal segment had survived until a (Common Sabellic?) stage *ns- had been reached, it is reasonable to assume that this sequence would have lost the nasal without lengthening in preconsonantal and final position.

${ }^{41}$ Like, for instance, -ns- was artificially transferred from written Latin to spoken Romance, as revealed by doublets like the Spanish abstract defensa vs. the inherited concrete dehesa 'pasture' < 'enclosure for cattle'.

${ }^{42}$ Cf. Meiser (1986: 70, 77), WOU: 463-464, 688-689, etc. 
*-dz- > -ss-, as in O. nessimass 'closest, nearest' (Cp 24, Capua), U. nesimei (Um 1 VIa) < nedzizVmo- $<{ }^{*}$ nezd-ismHo-.

Scribes may have hesitated as to whether it should be written or not, which explains $-<(n) z s>$ vs. $-<n s s>-$. The (in most cases) post-syncope sequence -ts(-) carrying no morphological information became a new affricate phoneme/ts/ in Sabellic. This is the case with Oscan forms like the conjunction puz 'that' (Po 39), the preposition az (if < *ads or *atVs, Sa 1, Agnone), or the dative vezkei (<*uetesk-, Sa 1, Agnone). The digraph $<z s>$ accordingly looks like a compromise spelling between $\langle z\rangle$ and $\langle s s\rangle$. But it may have been designed to distinguish /nts:/ from a postsyncope cluster /nts/. That is to say, the former may have become phonemically ambiguous if speakers of higher registers started to parse /ts:/ as a distinct tense dentoalveolar affricate phoneme. Lower registers may have tended to merge it with -ss-. The case of kvaizstur (Po 8, Pompei) for expected tkvaisstur may consequently be put down to hypercorrection.

The Venetic appellative a.n.śore.s. (nom. pl., LV: 203, Calalzo) occurs in a fragmentary context. It goes back to an Italic agent noun *antstōr-, ultimately (as if) from ${ }^{*} h_{2} n_{o}-+d^{h} e h_{1}-t o r-$ 'constructors; officials?' with zero-grade of the root by virtue of the «Italic» rule, according to which agent nouns are derived from synchronic past participles (see Prósper 2018b). The symbol $\langle\dot{s}>$ notes a tense sibilant. A much later, indirect instance of the preservation of this sequence is Ven. TATSORIAE in Emona/Šmarata (personal name, CIL III: 10722, Pannonia Superior), the full match of L. tōnsor (as if $<{ }^{*}$ tond-tōr). In this case, however, the excrescent dentaoalveolar stop may be the product of misperception of foreign names by Gaulish scribes who did not have that sequence in their native language, and the actual realisation of the stem may have been either [tons:o:r]- or [tonts:o:r]- (see Prósper 2019b: 52) ${ }^{43}$.

\subsection{The post-syncope cluster $-n(V) z-$}

The cluster going back to Italic ${ }^{*}-n V z^{-}\left(<\mathrm{IE}{ }^{*}-n V s^{-}\right)$evolved in different directions in Sabellic, too. As observed in 5.1., there is every reason to believe that post-nasal voiced fricatives are cross-linguistically dispreferred.

In Oscan, the weak sibilant, probably realised as [z] when it was still intervocalic, was spelt in the national alphabet as $\langle n s\rangle$, and the verb form patensins $<{ }^{*} p \partial t-n a-s \bar{e}$ - 'aperirent' $(\mathrm{Cm} 1 \mathrm{~b}$ 24-25, Abella) is our best example. As for Oscan in the Greek alphabet, the content of $\langle\zeta\rangle$ in

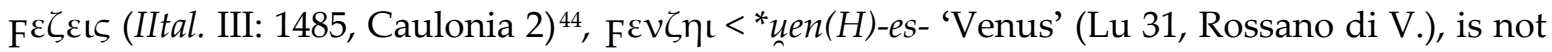
quite certain: while Lejeune (1970), followed by Stuart-Smith (2004: 97) believes it to be rendering an affricate, itself the product of the insertion of an excrescent dentoalveolar sound, it is more likely to represent a phoneme $/ \mathrm{z} /{ }^{45}$. Finally, MINSTREIS ( $\mathrm{Lu} \mathrm{1,} \mathrm{Bantia)} \mathrm{goes} \mathrm{back} \mathrm{to} \mathrm{*ministero-.}$ Across compound boundaries, - $n \# s-$ was probably realised as [ns:], as in O. $\kappa \omega \sigma(\tau)\llcorner\tau$ (Lu 5, Rossano di V) and perhaps kúnsíf deívúz < *kon-sent-s deinot-s, the divine name corresponding to the dei cōnsentēs, according to Poccetti (2013b: 35) ${ }^{46}$. Cf. IItal. II: 1183, Pentri/Terventum 22, c. 150-100 BC ${ }^{47}$.

${ }^{43}$ The Celtic outcome of *-Vntst- was $-\bar{V} s s-$, a sequence preserved in Eastern Gaulish and variously rendered attested in the Venetic record as $\langle\dot{s}\rangle,\langle s s\rangle$ or $\langle s\rangle$. For instance, the personal names le.s.sa (LV 208, Cadore), leso (LV 93, Este) are Gaulish derivatives from *splend-tu- 'splendor' (in OIr. lés 'light'). Cf. Prósper (2019a: 151).

${ }^{44}$ Omission of the nasal in coda position is trivial across languages and writing systems and is not necessarily caused by phonetic weakening and loss (see Méndez Dosuna 2007).

${ }^{45}$ As observed above, by this time, or in the southern region, the contrast had become one of voice, and /z/ was phonemic in every position except probably in auslaut and in codas, where the contrast had been abandoned and the sibilant acquired the voice specification of the following consonant.

${ }^{46}$ To my mind, however, deívíz, in view of its final letter, can hardly be a singular form, but a nom. pl. *deiuot-es, mutatis mutandis a match of the Latin expression. This leaves us with an insoluble problem that cannot 
In Umbrian, medial vowel syncope gives rise to an undesired sequence which, again, became stabilised by the intrusion of an epenthetic sound that blocked the nasal-fricative transition, yielding ${ }^{*}-n^{t} S^{-}$, which was subsequently phonemicised: cf. uze/ONSE 'shoulder' (<*omeso-, Um 1 IIb 27-28, etc.), the full match of L. umerus ${ }^{48}$. At any rate, we must assume an evolution ${ }^{*}-n V z->{ }^{*} n s->-n^{t} s->-n t s-49$. The sequence $-n \# s-$ across synchronically recognisable morpheme boundaries underwent the same stop excrescence and eventually became -nts-, as in U. anzeriatu, ANSERIATO 'let him watch' ${ }^{50}$. This is also the case with sequences containing an underlying dentoalveolar segment, like $-n t / d \# s-$ (as in the $3^{\text {rd }} \mathrm{pl}$. dep. fut. OSTENSENDI, Um 1 VIa 20, from *op(i)-stend-s-). Syncope in forms containing an inherited segmental $/ \mathrm{t} /$ gave rise to a new Umbrian phoneme /ts/ spelt $<z>$, as in kazi 'kettle' (<*katesim, Um 1 III 16, 18), ezariaf 'food' (<*edesāsiiio-, Um 1 IVa 27), pihaz 'piatus' (<* piātos, Um $1 \mathrm{Ib} 7$ ). As a consequence, the secondary, postnasal cluster was interpreted as phonemic.

The form menzne (loc. sg., Um 1 IIa) is habitually traced back to *mēn-s-(e)n-i 'moon', an adjectival derivative of *mēns- 'month' (cf. WOU: 471) ${ }^{51}$. Accordingly, the assumption that

be addressed here given our lack of evidence: kúnsif would have to be traced back to post-syncope *-V(:)nts, either regularly or by analogy with the singular form.

${ }^{47}$ After finishing this work, I have become aware of a very recent one by Fortson and Weiss (2019). They trace kúnsif to *ḱkons-eie- an iterative present of *kens- in Skr. à-śamsaya 'give hope', MW. dan-gos- 'show', and reconstruct PItal. *konse-- and *kens-e-, later conflated into *kens-ē-. The Oscan form would mean 'decreeing, approving'. This is a brilliant idea, if an early generalisation of the stem *kons-eie- as in Latin is accepted (the original sequence is *kons-eio-nt-). As they say (fn. 14) <i> has been reintroduced in analogy to forms containing $-\bar{e}-$, which cannot be the case with -sents. On the other hand, given the plethora of Latin loanwords of this root, kúnsif, if its immediate predecessor was /ko:se:/-, could have been influenced by them as regards preservation of $<n s>$ in this lexical field, or, like L. consentes, could have been reanalysed as a compound, especially if the legal term only attested in PRAESENTID (Lu 1, Bantia) had already been borrowed.

${ }^{48}$ Most recently, Höfler (2018) has reconstructed a preform ${ }^{*} h_{1} e m H_{o} s o-$ for this form and L. umerus 'shoulder', but the difference is in principle immaterial to the present argument.

${ }^{49}$ Even if a cluster [nz] had survived unchanged, epenthesis is unusual between two voiced segments, since continuous voicing causes less air pressure build-up and the stop burst is hardly audible, at least in the sequence [lz] vis à vis [ls] (Ohala 1974: 359; cf. also Akamatsu 2011: 91 on [nz] > [ndz]). The sibilant was probably devoiced after syncope and before stop excrescence. Apparent exceptions, like the Yiddish forms Gandz 'goose' and Haldz 'throat' may not presuppose a former stage with word-final voicing [ns] > [nz], [ls] > [lz], as often assumed, but epenthesis ['gans] > ['gants], ['hals] > ['halts] and subsequent voicing of the affricate (probably not before the dental sound was perceived as phonemic), as opposed to Fentster 'window' from ['fenster], in which voicing is blocked. The same explanation may apply to [ndza'lata] 'insalata' in Neapolitan, cf. [kan'dzone] 'canzone' (Rohlfs 1968: 363). Note that epenthesis is very rare, for instance, in English plurals like ten-s ['tenz], in which -z is not the improbable product of voicing after a nasal, but the basic inherited morph vis à vis secondary $-s$ and $-\partial z$. By contrast, it is the usual realisation of American English tense ['tents].

${ }^{50}$ Excrescence is absent in English compounds, e. g. gunshot ['g $\mathrm{n}$ fjt] vs. mansion ['mæntf(ə)n], because in the first case the speaker is aware of a virtual pause (see Akamatsu 2011: 109). But in the Umbrian case, an-is a recognisable but not especially productive bound morpheme; accordingly the boundary is ignored and excrescence occurs. Note, however, that excrescence does not occur or is dissimilated in anstiplatu 'instipulato' (Um 1 VIa).

${ }^{51}$ Note that the consistent Umbrian spelling <NS> in the Latin alphabet probably means that the sequence had been fricativised by the time the Tables were transliterated. It is the same in pihaz/PIHOs 'piatus' and consequently does not mean that we have two different outcomes in Umbrian and its dialects, one in which the sibilant has been voiced «qui ne peut être occasionée que par la proximité de [n]» and another with effacement of the nasal and no voicing that would be similar to Latin and supported by MESENE and ASERIATO, pace Poccetti (2006: 34), who believes Etruscan $\langle z\rangle$ to be employed in Umbrian in this context because it was noting a voiced sound [ $z$ ]. This is implausible, since the alphabetic usage is essentially phonemic and the allophonic voicing when a nasal precedes is unlikely to be consciously perceived as relevant and reflected in writing. Additionally, as we have seen, an evolution $[\mathrm{ns}]>[\mathrm{nz}]$ is hardly possible. 
original intervocalic -n.s- yielded U. /nts/ favoured the reconstruction of a single form *mēnsfor all the Italic languages. In view of the arguments displayed above in 5.1., however, one cannot attach much credence to the idea that primary ${ }^{*}$-ns- would have undergone preservation of the nasal segment and, in addition, epenthesis. Note, by way of comparison, that the Latin cluster $-n s n$ - is simplified even across (different) morpheme boundaries, as in *trans\#snō 'I swim across' > trānō and *kon\#snou ð/ $\beta$-iiio- > cōnūbium ${ }^{52}$.

The original structure of the word for 'month' is much of a locus desperatus of IndoEuropean reconstruction. It is usually held to have been a holokinetic noun of the genus com-

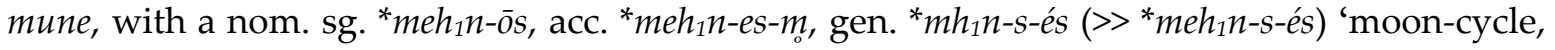
month' 53 , and then an original collective or simply an abstract derived from a $-s$-stem. Its locative would have been ${ }^{*} m e h_{1} n-e s(-i)$, with early analogical spread of the /e/ grade of the root and regular /e/ grade of the suffix. While the Baltic languages have forms going back to *mēn-es-, like Lith. mёnио 'month, moon' gen. ménesio, alternative nom. mènesis, or Latv. mènes(i)s, ProtoSlavic inherited a stem *mēn-s- (cf. Derksen 2015: 311-312). This points to a primitive paradigmatic alternation resolved by the daughter languages in different directions, and this may well have been the case with Sabellic *mēnes- vis à vis L. mēns-i-. The Latin form could actually go back to the genitive *meh $n$-s-és, which became the base of a -i-stem (with spread of the /e/ grade of the root) ${ }^{54}$.

I consequently assume that U. menzne has undergone medial vowel syncope and must be traced back to ${ }^{*} m \bar{e} n-e s-n$-ei, the dat.-loc. of a possessive adjective ${ }^{*} m \bar{e} n-e s-\bar{o}(n)^{55}$. The following alternative derivational paths are conceivable: a) The stem *mennes-, extracted from the accusative or locative form of the holokinetic formation, was thematicised into *men-es-o- and then received a nasal possessive suffix. b) A locative in -en, namely ${ }^{*} m \bar{e} n-e s-e n$, gave rise to an exocentric nasal stem derivative *mēn-es-ō(n). This is reminiscent of Nussbaum's classic explanation of L. homō as a derivative of a «double full grade» locative ${ }^{*} d^{h} g^{h} e m$-en, whether primitive or remodeled (1986: 189-190, 289). c) Finally, the bare stem *mēnes-, could have constituted the base for the construction of an adjectival derivative ${ }^{*} m \bar{e} n e s-\bar{o}(n)^{56}$.

Original *mennsnV- would hardly have become the attested Umbrian form, but probably ${ }^{*} m e f n V$-, or possibly * mēnnV- or * mēznV-, which would have contained stable consonant clusters. The traditional view equally falls short of explaining U. anter:menzaru 'intermenstruarum; occurring between two moons' (gen. pl. of an $-\bar{a}$-stem, Um 1 IIa). In fact, if the habitually reconstructed sequence *mēns $V$ - had undergone early stop epenthesis and become ${ }^{*} m \bar{e} n^{t} s V$-, nothing would have prevented it from becoming * $m \bar{e} f V$-, especially since inherited /ns/ would be intramorphemic. In any event, the reconstruction of a preform *mēnso-, with preservation and fortition of intervocalic *-ns-, is unconvincing, in spite of its close Avestan cognate antarz-

${ }^{52}$ Cf. Weiss (2009: 179) for other comparable sequences.

${ }^{53}$ See Beekes (1982, who starts from a -t-/s- alternation in the suffix, however), as well as Ruijgh (1967: 237) for Myc. me-no-e-ja /me:no:heia/, an adjective derived from * $m e h_{1} n-\bar{o} s$ and meaning 'decorated with moons'; more recent works in defense of the above holokinetic paradigm are, with slight discrepancies, e. g. Meißner (2006: 147150), Vijūnas (2009: V.9), and Rasmussen (2016: 325).

${ }^{54}$ This would mean that Italic exclusively inherited the holokinetic paradigm, not, as often believed, that of OIr. mís, Gk. $\mu \eta \dot{v}$, Skt. mās, in turn a homogeneous stem *meh $n-s-$, secondarily created from the genitive form.

${ }^{55}$ Syncope of the medial vowel in a closed syllable is equatable to that of U. MERSTO, from *med-es-to(cf. L. modestus). In fact, short vowel syncope in closed syllables which terminate in /s/ is regular in Sabellic and perhaps related to the fact that the resulting, seemingly complex codas must be parsed as coda + extrasyllabic sibilant, e. g. -VR.s.CV-. On the extrasyllabicity of Latin sibilants in this position, cf. Cser (2012).

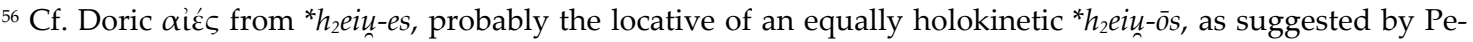

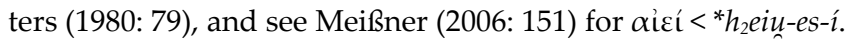


månha- 'between the moons'. It could be identical to the base of L. intermēstris, if from *mēnesri-, and then both forms would go back to a hypostatic compound * $h_{1} n_{0} t e r-+m e h_{1} n e s-$, in which the preposition governs an endingless locative (or alternatively an accusative, which would have an identical stem) ${ }^{57}$.

As regards Oscan and its dialects, the related Vestinian form MESENE (VM 9, MESENE FLVSARE 'in the month of Flora') ${ }^{58}$ may have gone through the stages *mennesnV- > ${ }^{*} m \bar{e} n e z n V->$ ${ }^{*} m \bar{e}(n) z n V->{ }^{*} m \bar{e}(n) z e n V$ - through voicing, syncope, nasal loss (or possibly just defective spelling) and anaptyxis ${ }^{59}$. Oscan post-syncope $-m s$ - became $-m^{p} s$ - by epenthesis in the divine name $v v \mu \psi \delta o \iota \mu \alpha \mu \varepsilon Q \tau \tau o l$ (dat., Lu 28, Rossano di V., c. 300 BC), which goes back to *numasiio-60.

In sum, Oscan and Umbrian differ as regards the outcome of post-syncope -ns-: while Umbrian consistently blocked the nasal-to-fricative transition by stop epenthesis, giving rise to $-n^{t} S^{-}$, the Oscan post-syncope cluster was spelt $\langle n s\rangle$, and $\langle v \zeta\rangle$ in the Greek alphabet, since /z/ now enjoyed phonemic status.

The so-called «Opic» or «Pre-Samnite» dialect that is often linked with South-Picene in the wake of Helmut Rix, but seems to share a number of traits with its Oscan superstrate, equally shows $\langle n s>$ and $\langle m s>$ in the recently uncovered inscription of Niumsis Tanunis (see below 8.). Venetic and Latin have followed different paths, since medial vowels are not regularly syncopated: the Latin voiced sibilant has undergone rhotacism, as in umerus 'shoulder'. In at least some Venetic areas, the voiced sibilant [z] was further weakened into an approximant, debuccalised and eventually effaced, as in the personal name voltigenei (dat. sg., $L V$ : 56, Este,

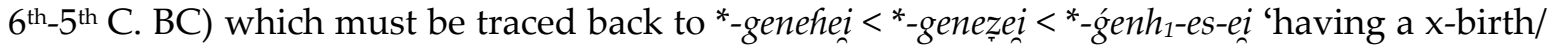
lineage' (cf. Prósper 2019a: 8-14).

\section{Italic sequences of rhotics and sibilants}

The above evolutions are partly paralleled by those of original vis à vis secondary clusters of rhotics and sibilants:

IE *-rs-, possibly with an early voiced realisation of /s/, is preserved in Umbrian, but assimilated in Latin, as transpires from unobjectionable cognates: cf. *torse- 'chase' > U. tusetu, TVRSITV (fut. impv.), L. torreō, ${ }^{*}$ torsa $\bar{a}>$ divine name U. turse, tuse, TVRSE (dat. sg.), TVRSA (voc.), and *fars- > U. farsiu, L. farreum 'made of, or related to, wheat'. The Oscan outcome of Italic *-rs-

${ }^{57}$ As repeatedly asserted in the literature, we would expect an adjectival form in *-(i)io-, and it has been suggested that it is a noun for 'Kalends' (cf. Weiss 2010: 28). It could consequently belong to a more archaic layer than the typical parasynthetic pattern found in Latin pomoerium, procastria, proverbium, suburbium, or the productive interdigitium, intermundium (see Bader 1962: 283). That is to say, the compound is of Proto-Italic date and belongs to the exocentric type originated in the thematicisation of a prepositional phrase attested in Gk. $\dot{\varepsilon} v \alpha \lambda i \dot{i} \rightarrow \dot{\varepsilon} v \alpha \dot{\lambda}$ ıo 'living in the sea', irvún 'hollow at the back of the knee' (< *en-ǵnuu-āa, cf. Forssman 1964: 29), Skt. ati-rātr-a- 'lasting more than one night', adhas-pad-a- 'found under the feet', and Av. antara-månh-a-.

58 See Segenni (2007) for this dialectal attribution.

${ }^{59}$ The new Oscan form minnaris is taken from * mēns- $n$ - by Poccetti (2013a: 213), who identifies it with the base of the Umbrian form. In view of the above considerations, his alternative, by which this is a reflection of *mēna, possibly identical to L. Mēnā and Gk. $\mu \eta \tilde{v} \eta$ 'moon' is more compelling (see more recently Poccetti 2016 in defense of the latter possibility). But this is not a usual context for the «flamma»-rule, which has led Weiss (forthc.) to identify it as a correlate of L. minuō 'diminish'.

${ }^{60}$ According to some scholars, the epithet contains a further suffix *-id-(i)io-(Lejeune 1970). This is refuted by Poccetti (2009: 230) who compares the name Nıu rendition of $/ z /$ by means of $\langle\sigma \delta\rangle$, but these testimonies are too distant and it would be really remarkable that this spelling norm was exclusively applied to this name. 
is $-\bar{V} r-$, as in teer [úm, tereí, etc. (<*terso-, cf. L. terra; Cm 1, Abella). This probably means that this evolution aligned with that of Latin, and that at an intermediate stage the cluster - $r r$ - was simplified with compensatory lengthening of the preceding vowel before medial vowel syncope.

IE *-rtst- becomes Proto-Italic *-rtss- (cf. L. vorsus 'turned'). This sequence survived into Proto-Sabellic. In Oscan, it evolved into $-r(t)_{s s-}$, as in the agent noun Fegooge 'Tropaios', epithet of Iuppiter (< ${ }^{*}$ uertsto $r-;$ Lu 25, Vibo Valentia) and in Umbrian into ${ }^{*}-r s_{-}-{ }^{*}-r \theta->-r f-$ in the adverbial past part. trahuorfi 'transverse' $(<*$-urtsto-; Um 1 VIIa 25). See further details in the conclusions of this work.

IE *-VrVs\# yields $-\bar{V} r$ in two nom. pl. forms going back to *-er-es: U. frater (Um 1 Va, etc.), frateer (Vb 16), O. ${ }^{*}$ neer (recovered from a putative gen. pl. neer[um, cf. IItal. II: 674, Pompei 32). This indicates that final vowel syncope was followed by progressive assimilation, simplification of the geminate sound and compensatory lengthening of the preceding vowel: ${ }^{*}-V r_{s} \#>$ *-Vrr\# $>-\bar{V} r$.

IE * $r V s$ - is unanimously held to show disparate outcomes in Sabellic: in Oscan, after voicing and syncope, ${ }^{*}-r z$ - undergoes assimilation and surfaces as - $r r-$. The symmetry is destroyed by the alleged Umbrian outcome $-r f$ - (or $-r \beta$-). And yet, none of the examples adduced thus far in favour of the latter evolution is compelling: crucially, Weiss (2017) has recently disposed of the validity of the traditionally accepted equation of U. çerfe/SERFE (Um $1 \mathrm{Ib}, \mathrm{VIb}$, etc.), Pael. CERFVM, ${ }^{61}$ O. kerrí 'Cereri' (dat. sg. < *kerez-ềi, Sa 1, Agnone), etc., all of them traditionally traced to ${ }^{*} k e r V z V$ - and identified with the divine name Ceres or derivatives thereof. Weiss has favoured a connection of the first two forms with Skr. śardha- '(military) troop', usually applied to the Marutas. This is much more compelling since it furnishes an explanation for the apparent alignment of Paelignian with Umbrian, and spares us from accepting divergent outcomes within the Oscan family.

As a consequence, we are now left with a single instance of the evolution ${ }^{*}-r V z->-r f / \beta-$ : the birdname U. parfam/PARFA (Um $1 \mathrm{Ib}, \mathrm{VIa}$ ), purportedly identical to L. parra 'small bird', and traditionally traced back to ${ }^{*}$ parVzV-. Parfa and parra probably designate a sparrow or another sort of small bird involved in ritual divination in Umbrian and related to either ill or favourable omen in Latin, where it is attested since Plautus ${ }^{62}$.

To begin with, the acceptance of an Umbrian sound shift ${ }^{*}-r V z->-r f-$ silently relies on the idea that Latin -rr- must inevitably go back to IE ${ }^{*}-r(V)_{s-}$. What is more, the purported Umbrian evolution runs up against serious difficulties: as we have seen, Umbrian * $n V z-$ evolved into $-n^{t} s^{-}$. In logic, we would expect ${ }^{*}-r V z$ - to yield Umbrian $-r s^{-}$, or to undergo progressive assimilation to - $r r-$, as in Latin and Oscan, or even to undergo epenthesis and surface as $\langle r z\rangle /$ rts/ (see more on this possibility in the conclusions). The acceptance of a sound change ${ }^{*}-r V z->-r f$ - simply begs the question and takes advantage of the untenable assumption that /s/ in a number of contexts may straightforwardly become $/ \theta /$ (and eventually /f/) in Umbrian without intermediate stages that look minimally plausible ${ }^{63}$. I conclude that, since forms of a

${ }^{61}$ In the renowned Herentas-inscription (Pg 9, Corfinium).

62 Plautus mentions parra as the herald of good omen: picus et cornix ab laeva, corvos, parra ab dextera consuadent (Asin., 260-261). Cf. Fisher (2014: 79-81) on the possibility that the couple U. peico/parfa vs. picus/parra continues an inherited list of augural birds belonging to a single archaic Italic ritual complex; the Iguvine Tables prescribe that the parfa should be seen from the right, too (parfam tesvam, PARFA DERSVA). This points to these forms being identical after all. In turn pārus 'tit' could be the inverse, hypercorrect product of the «flamma»-rule. Note that if pārus were original and parra its alternative realisation, parra and parfa would be ipso facto unrelated.

${ }^{63}$ Bear in mind that this objection does not apply to the shift (-)sr->(-) $\theta / \partial r->(-) f / \beta r-$. (-)sr-is a comparatively unnatural or difficult cluster, resolved in western Indo-European by stop insertion (-)sr- > (-)str- (as in Germanic, Slavic, Old Prussian, Latvian and most Balkanic dialects), by assimilation $/ \mathrm{sr} />/ \mathrm{r} /$, or by loss of stridency (as in Italic and part of Celtic). 
comparable structure in other languages are lacking, and the proposed evolution reveals a blatant internal asymmetry with that of $-n V z-$, an etymology containing an intervocalic sibilant is unreliable, and post-syncope ${ }^{*}-r z$ - is unlikely to have evolved into $-r f / \beta$ - anywhere. It should be clear by now that a Sabellic sibilant only surfaces as Umbrian and South-Picene $-f$ - in the neighbourhood of $/ \mathrm{n} /$ and $/ \mathrm{r} /$ when there is also a dentoalveolar sound at play, whether inherited or intrusive, but never in post-syncope environments. A birdname (itself a class of names very prone to borrowing) with ritual associations and far from transparent origins does not qualify as a candidate to fill the gaps of Italic sound-change reconstruction.

In addition, the word-formation presupposed by the traditional etymology is far from convincing: the root is usually held to be *(s)per- 'fly' (see LIV: 579), but evidence for a -s-stem of this root is non-existent. Recently, Höfler (2017: 17-18) has ingeniously traced U. parfa, L. parra to an adjective *sprH-s-ó- 'feathered' (belonging to the russus-type), allegedly paralleled by the

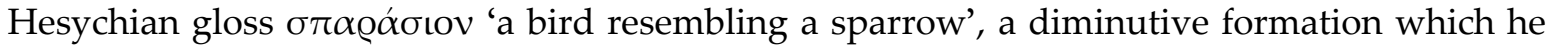
ascribes to Magna Graecia. But, even if the last point were true (albeit there is not the slightest hint of it in our only extant source), late loss of word-initial $s$ - in the attested Italic forms calls for an explanation ${ }^{64}$. It has been suggested (Prósper 2020) that the so-called «palma»-rule should be formulated as \#CŔH.C- > \#CáRH.C- > \#CáR.C- with laryngeal loss and lowering of the central vowel under the accent. In fact, the traditionally posited outcome \#CáR.Ho.C- is phonotactically suspect and unparalleled, except for the dubious case of Greek which has always constituted its model. This would make the intermediate structure *parazV-ipso facto unwarranted: we would expect either PItal. * prāzē (> U., L. * prārāa) or * pars $\bar{a}\left(>\mathrm{U} .{ }^{*} \text { pars } \bar{a}, \mathrm{~L} . \text { parra }\right)^{65}$.

I alternatively reconstruct this birdname as ${ }^{*}(s) \mathrm{pr}(H)-\mathrm{g}^{h} h_{1} u-o /-e h_{2}$ 'flying-goer', which straightforwardly accounts for U. parfa. It should have given L. tparva, but underwent expressive gemination (as in other animal names like peccus, cattus, vacca and probably viverra 'ferret'), which prevented homonymy with parva 'small', and glide absorption. While this resyllabication of a heterosyllabic structure -C.u- is well attested in epigraphy, as in IANNVARIVS, FVTTVERE, ACQVA, and probably indicative of a lower phonostyle, the eventual loss of the glide (in fact very common in the Romance continuants of these forms), may be put down to the auditory difficulties inherent in the perception of a cluster ${ }^{*}$-rru-, owing to the minimum distance of its constituents in the scale of strength ${ }^{66}$. This phenomenon also lurks behind the Umbrian evolution ${ }^{*}-r u->-r r$ - in *kateru $\bar{a}>{ }^{*} k a t e r r \bar{a}$, as reflected in the denominative verb kateramu 'arrange yourselves in catervae' (Um $1 \mathrm{Ib} 20)^{67}$.

The conceivable cognacy of Italic and other European bird names may now ne explored:

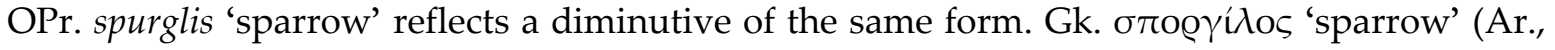
$A v$. 300), which can equally be derived from our reconstructed *(s)pr $(H)$-gh $h_{1} u_{0} 0$ - or to *(s)por(H)$\mathrm{g}^{h} h_{1} \mathrm{uO}_{\mathrm{O}-}$, is particularly interesting because it has undergone all the sound laws proposed by

${ }^{64}$ Additionally, there is the minor inconvenience that the Italic form would be ${ }^{*}(s)$ parazo- with a voiced sibilant; unless Hesychius' sources were very early, we would expect this phoneme to be spelt $\langle\zeta\rangle$.

${ }^{65}$ We could perhaps even expect L. *prass $\bar{a}$ if this was an originally rustic word preserving the original *prāza reinterpreted in urban Latin as /Vss/, as per Vine (2016, to explain grossus, crassus). Given the Latin fate of IE /Vns/, we could alternatively expect * prāz $\bar{a}$ to be adopted as *prās $\bar{a}<p r a n s a>$ which, given the expressive nuances associated to these forms, could surface as prassa by the «flamma»-rule.

${ }^{66}$ See Méndez Dosuna (1994) for this phenomenon in Greek.

${ }^{67}$ One could of course assume that the early outcome of IE ${ }^{*}-\mathrm{rg}^{h} u$ - was ${ }^{*}-r f u$-, which may have become ProtoLatin *-rru- by (context-bound!) assimilation of a glottal fricative to a preceding sonorant. Such an intermediate stage is phonetically plausible and may be reconstructed for Proto-Italic. In the mutatis mutandis comparable case of * $h_{2}(e) n g^{u h}-i->$ L. anguis 'snake' we reckon with a PItal. stage *-ngu- with occlusivisation after a nasal segment. Since we lack any other instance of the evolution of this cluster in Latin, this argument cannot be pursued here. 
Vladimir Georgiev for Pelasgian, an unidentified Indo-European substrate language which is only known through a number of Greek borrowings, like $\tau u ́ \mu \beta o \varsigma$, the match of $\tau \alpha \dot{\alpha} \phi o \varsigma^{\prime}$ 'tomb', or túp yos 'tower', the match of Goth. baúrgs, Celtic brig- 'elevated village', etc. ${ }^{68}$ In fairness, there are variants of this very form which do not conform to the pattern in that they show the

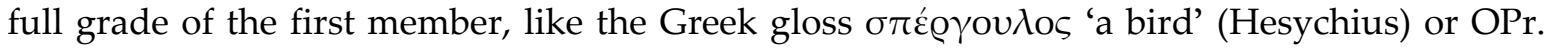
sperglawanag 'hawk'. While, mostly on the strength of the Germanic forms, some forms are said to come from a variant form ${ }^{*} s p V r-u_{0} o_{-}$, the examples adduced to this effect are very doubtful: OE. spearwa, etc. 'sparrow' can be traced to ${ }^{*}(s) p o r(H)-g h h_{1} u-o-$. ${ }^{B}$ Toch. sparä-yäkre 'kind of bird', related to AToch. șpār 'sparrow?", is traced to earlier *șpārā, and ultimately to

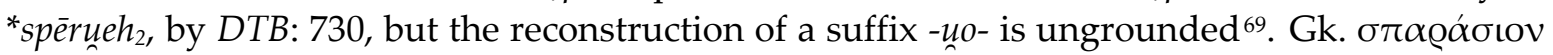
is also taken from ${ }^{*} \sigma \pi \alpha \varrho \mathrm{F}-\alpha \sigma^{*} \iota \mathrm{v}$ by EDG: 1375 on the strength of the Germanic forms. But, again, the reconstructed ${ }^{*}-u$ - has left no trace, and consequently there is neither comparative nor internal basis for introducing it.

As conceded in passing by LIV: 579, the anit nature of the root ${ }^{*}(s)$ per- is disputable. Koch (1990 I: 431) has drawn attention to its set character in Slavic. Both Albanian fier 'fern' and OCS. pero 'feather' reflect ${ }^{*}(s) \operatorname{per}(H) o m^{70}$. The Tocharian forms ${ }^{A} s \underline{p} \bar{a} r$, Bșparā- can consequently be traced back to a possessive vrddhi-derivative *(s)pērHo- 'endowed with feathers' > 'bird'. If the Greek form $\sigma \pi \alpha \varrho \alpha$ otov is correctly transmitted ${ }^{71}$, it could contain the regular outcome of an earlier *sprH-ó-, which saves us from resorting to the Lindeman effect. What is more, it might

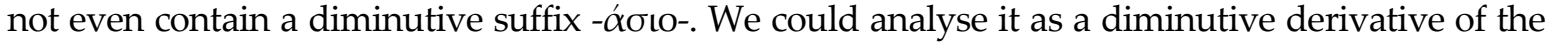
root participle *sprH-nt- 'flying', which would make this form the only remainder of the verbal inflection of this root outside Slavic. A new suffix -óoı- may in fact have been metanalysed from original *-nt-iiio- once this structure became opaque, as already contended by Solmsen (1907).

Along the same lines, Zair (2012: 98) has tentatively suggested that MB. frau, B. frav (m.) 'crow, jackdaw', from *sprăuo-, is similar to Goth. sparwa, etc. and perhaps L. parra, U. parfa, and has posited «a root ${ }^{*}(s)$ perH-, in which case the Greek and Germanic forms would represent $o$-grade ${ }^{*}$ sporH-u-on- and ${ }^{*}$ sporH-g- respectively (with loss of laryngeal in Greek by the Saussure effect), Old Prussian the zero-grade (though with a formation extremely close to that of Greek), and Italic a derivative of an old s-stem, hence ${ }^{*} p r H$-es-eh . The Celtic forms would then point to *spriH-uo- >*sprăuo-».

As we have seen, however, there is no basis for reconstructing a suffix *-uo-. The inclusion of the Celtic form in this group is accordingly contingent upon the assumption that the Brit-

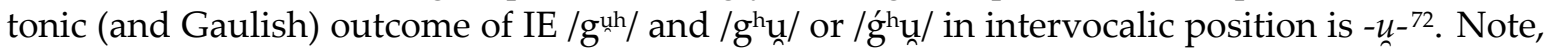

${ }^{68}$ Most recently, Mihaylova (2016) has vindicated the validity of Georgiev's tenets and has enumerated the features of this lost IE dialect: Grassmann's law, post-Grassmann consonant mutation, delabialisation of labiovelars and $[\mathrm{u}],[\mathrm{o}]$ as the outcome of vocalic sonorants, which probably means that a sound [u] was variously parsed according to context. Under these premises, our form may have undergone the following changes: [r] $>$ [ur], delabialisation *-gh ${ }^{h} \boldsymbol{u}_{-}{ }^{*}-g^{h_{-}}$, and «Grimm»'s mutation ${ }^{*}-g^{h_{-}}>-g$-. The word-initial cluster *sp-is an exception to the rule because, as in Germanic (E. stand, etc.), the sibilant blocks the fricativisation of the voiceless stop in order to avoid an undesirable sequence of fricatives.

${ }^{69}$ The very idea that IE *-ru- gives PToch. - $r$ - relies on the prejudice that an inherited suffix *-uo- must have

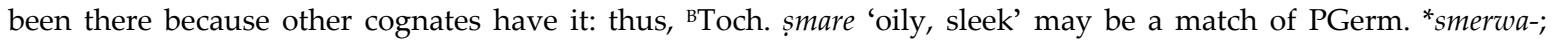
needless to say, this is strictly hypothetical, and fatally gainsaid by the preservation of the approximant in ${ }^{\mathrm{B} T o c h}$. śerwe 'hunter', which contains the same sequence.

${ }^{70}$ Cf. Schumacher et al. (2013: 218), Derksen (2007: 396).

${ }^{71}$ It is, in fact, misplaced, since the gloss occurs as nr. 1398, which would be fitting if the reading were

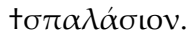

72 As contended by Koch (1992) in the footsteps of Cowgill (1980), who first put forward the idea that IE /guh/ was preserved as a voiced labiovelar in Proto-Celtic. This is based on the equation OIr. guidid= Gaul. uediIumI 


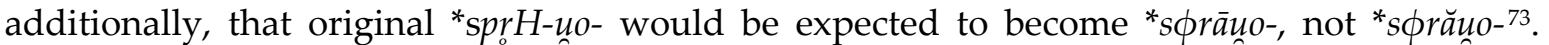
Conversely, the short vowel would probably be regular if we start from Proto-Celtic ${ }^{*}$ s $\phi r a{ }^{\prime}{ }^{u}{ }^{u}{ }^{74}$.

To recap: there is not a single indication that there have ever been any-s-derivatives of the root *sper(H)- 'fly'; all the conceivably related compounds or suffixal derivatives are in principle compatible with a sequence ${ }^{*}-g^{h} \underline{u}-$, not $-\underline{u}-$. We may consequently reconstruct a secondarily thematicised compound *(s)prH-gh $h_{1} u$ - which evolves into the expected forms in Italic (under acceptance of the «palma»-rule), Celtic and Baltic, and possibly the Greek substrate borrowing, whereas Germanic certainly reflects an /o/ grade and Baltic and Greek have variant forms with the /e/ grade of the first member, which show no trace of a laryngeal. This leads me to suspect that they may be due to a crossing of ${ }^{*}(s) p_{0} H-g^{h} h_{1} u$ - with the external derivative of an acrostatic noun *spelorğh $\mathcal{u}$ - 'speedy thing'. In fact, the root *sperğh- 'hurry up' (LIV: 581) is likely to go back to a univerbation of *sper(H)- + g'heH- 'move' (cf. LIV: 153) ${ }^{75}$.

Let us say, as a corollary, that there is at least one form in which ${ }^{*}-r V s$ - may be held to have eventually become $-r z-$ (or $-r s-$, since rhotacism never occurred): çersiaru is an adjective in the gen. pl. fem., or more probably a month name (see Weiss 2010: 28), accompanying antermenzarum (Um 1 IIa). While WOU: 391 provides a number of reconstructions, the most promising of which presuppose a base *kerts- or *kers-, the identification of this form with an adjective *keres-iio- is satisfactory in phonetic, formational, semantic and cultural terms. This preform is then identical to Pael. CERRIA, O. kerríiaí, etc. (L. cereālis may be dissimilatory or haplological for ${ }^{*}$ cerer-älis, or even replaces a syncopated $\left.{ }^{*} c e r r-\bar{a} l i s\right)$ and only the problems concomitant with the equation of U. parfa and L. parra and their stubborn attribution to a non-existent -s-stem have presented an obstacle to the obvious solution ${ }^{76}$. If we rule out U. çerfe, etc. as allusions to the goddess Ceres in the wake of Weiss (2017), the rich Umbrian pantheon is deprived of one of the most important Italic divinities, unless we call other flawed reconstructions into question. A very ancient adjective *kerh ${ }_{1 / 3} e s-o ́-$, based on the early but innovative double-full-grade oblique stem, is probably attested in the L. divine name Cerus, only attested by Paulus ex F. 109 Lindsay «in Carmine Saliari Cerus Manus intellegitur creator bonus», and duonus Cerus in Varro. Either this form or more probably its nominal base *kerh $h_{1 / 3} e s-$ 'Ceres' was enlarged by a relational suffix *-iio- (as in Venus, venerius) and became Proto-Italic *kerVz-iio-. This form was

(Chamalières) 'pray', later confirmed by the root participle ${ }^{*} g^{u h} e d^{h}$-ont- in the Celtib. family name kuezontikum (gen. pl., Botorrita III, see Beltrán et al. 1996: 144), and also on the equation of OIr. gonaid, W. gwanu, confirmed by the Celtib. personal name GVANDOS, in my view from the past part. * $g^{u h} n_{o}$-tó- (Peñalba de Villastar), which is identical to OIr. goite (gen. pl., Milan Gl. 77a19).

${ }^{73}$ As per Schumacher (2004: 136), partly on the strength of *prH-ti- 'fern' > PCelt. * ${ }^{*}$ rati-. Cf. also Lith. papártis 'fern'.

${ }^{74}$ Note that the set of names presumably meaning 'shining' like Baedro, Baedronenses, the personal name BAEDARI (gen., CIL III: 1585, Dacia), the ethnonym Baedui, which can be traced back to * ${ }^{u}{ }^{u h}$ eh $_{2} i d$ - (Prósper 2019a: 8) on

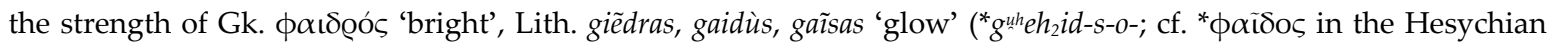

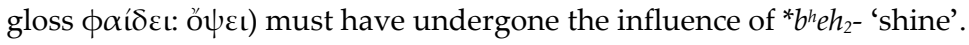

${ }^{75}$ For both roots, only the Avestan testimony speaks in favour of the reconstruction of a palatal sound. Given the existence of Skt. vanar-gú- 'traversing the wilderness', etc., compared with Lith. žmogùs 'man', from * $d^{h} g^{\prime h} m e h_{2}-g^{u} h_{2} u$ 'walking on earth' by García-Ramón (1985: 56; the appurtenance of the second member is ambiguous in Baltic), we can start from *(s)prH-g $h_{2} u$ - This explains the Greek form straightforwardly (a similar compound $\pi \varrho \varepsilon ́ \sigma \beta \nu \varsigma$ has a dialectal variant $\pi \varrho \varepsilon ́ \sigma \gamma \cup \varsigma$ 'old man, ambassador'), but not U. parfa.

${ }^{76}$ Burroni (2016) definitely abandons the connection of çersiaru with Ceres and ingeniously proposes a 'harvest month', either from a root *kers- 'reap, cut', via an action noun *kersó-, or from an (unparalleled) sibilant stem, and then from *ker-s-ó- 'having a cutting'. In his footsteps, Weiss (2017: 373) reconstructs *kers-iio- 'pertaining to

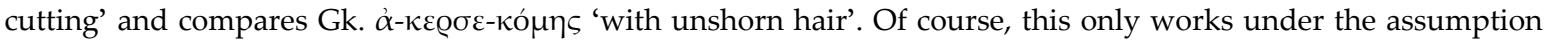
that ${ }^{*}-r V z$ - must become $-r f-$. 
as likely a candidate to acquire a specialised meaning as a month's name as many other adjectives derived from divine names in Italy by means of the same suffix. In other words, IE *-rsand IE ${ }^{*}-r V s-$ simply merged in Umbrian after medial vowel syncope ${ }^{77}$.

\section{Conclusions}

As repeatedly observed by previous scholarship, Proto-Sabellic is especially difficult to reconstruct as a homogeneous language previous to differentiation is Oscan, Umbrian and SouthPicene, because it has undergone such a plethora of innovations crossing the territory from different points and at different times (and often shared by Latin, Venetic and Etruscan) that a genealogical tree cannot be drawn with any confidence.

As implied above, one of the battlehorses of the Sabellic controversy is the date of medial and final vowel syncope. Benediktsson's assertion that the final vowel syncope took place after the shift -ns>-f/-ss, and for this reason the new, post-syncope cluster - $n s$ was never affected by further changes, ${ }^{78}$ is quite plausible. The preconception that syncope must have occurred prior to the dialectalisation of Sabellic has no basis, and the respective outcomes of Pre-Samnite and Oscan on the one hand, and Umbrian and South-Picene on the other, often differ simply because they are independent. Rix's ideas are further conditioned by the prejudice, already to be found in Buck (1904: 72), that the evolution of *-nt-s $(>-f)$ presupposes an intermediate stage $-n s$ and is therefore posterior to that of original ${ }^{*} n s$ (O. $-s s, U .-f$ in the acc. pl.). This makes the homogeneous outcome of *-nt-s impossible to come to grips with and generates a complex battery of unwarranted steps, essentially intended to account for the disparate outcomes of «primary»*-ns.

Languages respond differently to the problems inherent in the nasal + fricative transition. Sometimes, the nasal segment is effaced, often, but not necessarily, with concomitant lengthening of the preceding vowel. As we have seen, this change has been recently explained as auditory in nature. In my view, this is what actually happened at one or more stages to the Proto-Italic sequence $-V n . s V$-. By contrast, $-n s^{-}>-s s-$ is a less likely evolution (see the arguments against an assimilation /ns/ > /s:/ in Recasens 2018: 165-167). For instance, the fact that the primary se-

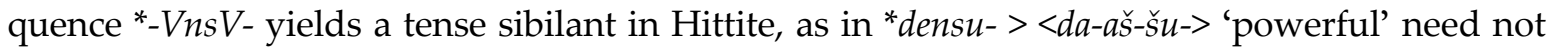
be indicative of regressive assimilation, but of a process very similar to the one depicted for Italic in this work: loss of $/ \mathrm{n} /$ created a secondary contrast between the new intervocalic tense sibilant (in turn lenited in Hittite in some contexts) and a lax sibilant that continued IE intervocalic/s/, while the contrast between ${ }^{*}-V n s \#$ and ${ }^{*}-V s \#$ may have been abandoned early on ${ }^{79}$.

\footnotetext{
77 Note that the Latin adjectives sin-cērus 'sound, whole' possibly < 'of one growth', and especially prōcērus 'tall' < 'having a high growth', usually taken from *'kêrh $h_{1} 0$ - or *kreht-ro- (see EDLIL: 491 for details), could alternatively go back to this very form *kerh ${ }_{1 / 3} e s o ́-$, which would phonetically give *kerro- but could have undergone hypercorrection (undoing the action of the «flamma»-rule and perhaps thereby favouring a less «rustic-flavoured» sequence), and it could merit a separate research to find out whether this is more likely to happen in compounds. It should be borne in mind that the divine name Cerus may have undergone the same process, and the testimonies of Paulus and Varro may thus have contained a long vowel /e:/ instead of a long /r:/ that was not noted in their early Latin sources. In fact, these forms could be thematicised residues of the ancient compositional schema X-R(e)-S(e)exemplified by IE * $h_{1} s u$-ǵenh $h_{1}$-és, etc. See more on the involved root and the reconstruction of L. crassus as * kr $h_{3}-s-o ́-$ in Vine (2016: 138-139).

${ }^{78}$ Cf. Benediktsson (1957: 258).

${ }^{79}$ The idea that we have to start from a Proto-Anatolian tense sibilant/s:/ in the context $-V n s s V-,-V m s s V->$ $-V s s V$ - is not contradicted by examples hinting at a tense sound, as in IE * Vsn $V$ - > Hitt. $-V s s n V-$ and $-V s r V->-V s s r V-$
} 
Occasionally, however, progressive assimilation takes place. As a result, a sequence $-V n . n V$ - emerges. This, however, is favoured by a weak realisation of the sibilant, which may have evolved into an approximant-like [s] or a glottalic [h]. This was never the case in Italic, though it might explain the Oscan and Latin assimilation *-Vr.sV- ${ }^{*}-V r r V-80$.

Finally, an excrescent homorganic stop may block the contact between the sonorant and the sibilant. This is an articulatory phenomenon, but the reason why the epenthetic sound is reproduced intentionally by the listener lies in his failure to understand the hearer's intention and discount it; as a consequence, the excrescent sound is phonemicised and reflected in writing (see Ohala 1997). In their classical study, Fourakis et al. (1986) observe that the nonetymological dentoalveolar sound is slightly shorter in duration than the inherited one. Recent experiments have shown that conscious perception of unintentionally produced excrescent sounds is comparatively high (but far less frequent than that of intentionally produced sounds). It is comparatively unusual that excrescent stops are parsed as underlying segments and trigger historical sound change over time, which may be partly explained by the influence of orthography besides production variability (see Warner et al. 2001: 81-82). In this work, I have tried to show that it is the previous existence of an underlying segment $/ \mathrm{t} /$, but also, in some contexts, the excrescence of a dentoalveolar sound, that constitutes the ultimate explanation for a number of Sabellic sequences at a pre-documentary stage.

The above assumption allows us to bridge the distance between original /s/ and Umbrian /f/. The comparative verisimilitude of a Sabellic language having merged the IE voiced aspirates $/ \mathrm{g}^{\mathrm{uh}} / \mathrm{,} / \mathrm{b}^{\mathrm{h}} /, / \mathrm{d}^{\mathrm{h}} /$ and the fricative $/ \mathrm{s} /$ into $/ \mathrm{f} /$ is contingent upon the situation of the cluster in question in the following hierarchy: the (Indo-European) presence of an underlying dentoalveolar segment $>$ the (Sabellic) emergence of an excrescent dentoalveolar sound $>$ the (postsyncope, exclusively Umbrian) emergence of an excrescent dentoalveolar sound.

a) The presence of an inherited segment /t/ generates Oscan, Umbrian and probably South-Picene /f/ in word-final position.

Only original *-nts\# became ${ }^{*}-(n) \theta \#$ and eventually $-f \#$ in all the Sabellic dialects, probably at a very primitive, Proto-Sabellic stage. These dialects show $-f$ in the nominative singular masculine of the active participles, which results from the fusion of the suffix -nt- and the nominative ending of the common gender $-s$. Later on, Oscan, or perhaps only its Campanian variety, transferred $-f$ to the nom. sg. if the $-n$-stems. This transfer probably never took place in South-Picene and cannot be claimed for Umbrian, as has been previously done, on the meager grounds that the $-f$ is not reflected because of late Umbrian weakening or defective spelling. As a consequence, Oscan iaf cannot be the acc. pl. of a feminine anaphoric pronoun *eiā, but only the nom. sg. masc. of the root participle ${ }^{*} i-n_{0} t-s\left(\ll{ }^{*} h_{1} i-e n t-s\right.$ by paradigm leveling), preserved in L. iēns and Ven. *iant-. The word final sequence ${ }^{*}-(V) n t s \#$ merged with *-(V)ns\# in Latin and eventually surfaced as $-\bar{V} s$.

As in the case of U. traf 'trans' < *trănts, it is unclear whether iaf has undergone compensatory lengthening or not. The Umbrian forms in -ef have undergone Osthoff's Law at the stage ${ }^{*}-\bar{e}-n t-s$ and are invariably spelt with $\langle e>$. This means that the Oscan present participles statif and kúnsif, whether they ultimately go back to ${ }^{*}-e n t-s$ or ${ }^{*}-\bar{e}-n t-s$, should in principle have been

vis à vis the lax outcome of $/ \mathrm{s} /$ in $-V s m V-,-V s l V$ - and the assimilation in - Vrs $V->-V r r V-$. There is no other case of the alleged regressive assimilation of $/ \mathrm{s} /$ in any consonant cluster, even those which constitute a cross-linguistically favourable context, like -ts-, - $k s-$ : they preserve the stop and undergo fortition of the sibilant, like $\mathrm{ClsV}-$, $C r s V-$ (cf. EDHIL: 71-73). A homogeneous treatment of the Hittite internal evidence runs counter to the suggested assimilation. On the other hand, Simon (2020) has vindicated the contrast between voiceless and voiced phonemes in Hittite, which can be extended to sibilants.

${ }^{80}$ For Greek* -Vr/n.hV-> -VrrV-, -VnnV-, see Méndez Dosuna (1994: 111). 
rendered tkúnsef and <i> (phonemic /ẹ/) must be analogical. This is unclear in view of our paltry evidence.

b) The inherited sequence ${ }^{*}-V t^{s} t V$ - became Proto-Italic $-V s s V-$, but ${ }^{*}-V n / r t^{s} t V$ - became $-V n / r . t s s V-$.

Consequently, /t/ was an underlying segment in this context. Later, $-n$.tss- became $-f$ - and -r.tss- became -rf- in Umbrian and possibly South-Picene, but remained -tss- in Oscan, at least in the neighbourhood of nasals. Given the post-syncope emergence of an affricate phoneme $/ \mathrm{ts} /$, its phonemic status may have become ambiguous and it is rendered $\left\langle\right.$ ss $>$ but also $\langle z s\rangle{ }^{81}$.

c) IE *-ns.C-, ${ }^{*}$-ns\# and ${ }^{*}$-ns \# in coda and word-final position result in Umbrian and SouthPicene $-f$, but Oscan (and probably Venetic) -ss, and Rix's postulation of a common stage $-f$, followed by a cascade of analogical processes, has nothing to recommend itself. What is more, the evolution $-n s>-f$ tacitly demands a leap of faith. It can hardly be explained in phonetic terms except by admitting the intrusion of a (subphonemic) dentoalveolar sound that blocked the nasal-to-fricative transition and yielded Sabellic (and probably Venetic) ${ }^{*}-n^{t} s$. This turns the scales in favour of a radically different relative chronology from the one assumed so far.

After the nasal was lost, compensatory lengthening of the preceding vowel did not take place, either because the syllable stayed closed or because the epenthetic dental stop was still there; the Sabellic thematic endings are consequently analogical. The Latin outcome $-\bar{V}_{S}$ is suggestive of the generalisation of the prevocalic outcome, but one could go so far as to posit an evolution ${ }^{*}-V n^{t} S>{ }^{*}-\tilde{V}_{S S}>{ }^{*}-V s S>-\bar{V}_{S}$ (where compensatory lengthening would be due to simplification of the geminate and not to nasal loss). Final $-s$ and -ss never contrasted in Latin, and $-\bar{V}_{s}$ eventually merged with the nom. sg. ${ }^{*}-V n t-s$ anyway. Under a completely unitary picture, we could place the Italic languages at different stages of an evolution ${ }^{*}-V n^{t} S>{ }^{*}-\tilde{V}_{s}(>-\tilde{V} S$ $>-(V) \theta>-f$ in Umbrian) $>-\tilde{V}_{S S}>-V s S$ (Venetic; $-s s$ by final syncope in Oscan) $>-\bar{V}_{s}$ (Latin). Even if the first stage had been shared by all the dialects, it can only have been reached after ProtoSabellic *-nts evolved into *- $(n) \theta$.

As we have seen above, the hypercharacterisation of the nom. sg. of nasal stems can at present be held to have affected Oscan (or at least its central dialects), and cannot be described as a process ${ }^{*}-n s \#>-f$, but as a mere transference of the synchronic ending $-f$ from the $-n t$ stems to most or all nasal stems ${ }^{82}$.

d) In Umbrian, the post-syncope cluster -n.s- and the cluster - $n \# s-$ across a compound boundary underwent excrescence of a dentoalveolar stop, yielding $-n .^{t} s_{-} ;$this onset was phonemicised as /ts/ and spelt $<\mathrm{z}>$ and experienced no further changes. In Oscan, the cluster $-n . s^{-}$ suffered no visible changes. The originally intervocalic sibilant was parsed as a lax phoneme, and later (or dialectally) as a voiced phoneme judging by the orthographic conventions, but,

81 This is why the Italic word for 'dinner' is unlikely to go back to *kert-sna (EDLIL: 106). The rendition of the sibilant in this context shows some hesitation in O. kerssnaís, kersnu, kerssnasiais, kersna<t>iais. It is the full match of U. çesna 'food' (Um $1 \mathrm{Vb}$ 9), çersnatur 'having had dinner' (Um 1 Va 22, past part., nom. pl.) and L. cēna. According to WOU: 393, this form ultimately goes back to *kertesna, but this is unwarranted, since it would have become L. ** certèna. This form may be traced to *kers-snā (LIV: 355-356 $\left.{ }^{2 *} k e r s-~ '(a b) s c h n e i d e n '\right)$.

82 The extension of this idea to the $-r$ stems, whose nom. sg. would have been remodeled as * ${ }^{*}$ s in ProtoSabellic according to Rix (1986: 592-593) fares no better, since it is exclusively predicated on the high spelling frequency vis à vis omission of final $-r$ in Umbrian. In Rix's words, ${ }^{*}-r s$, like the syncopated nom. pl. -res, has preserved a «strong» $-r$, the product of progressive assimilation. The question actually revolves around the analysis of two forms in -tōr, arffertur, AR(S)FERTVR and kvestur, in which - $r$ is more consistently spelt than in the passive endings in $-r$. Nominal stems have been strongly influenced by the rest of the paradigm, however. If the nom. pl. U. frateer, O. *neer bear witness to compensatory lengthening of the preceding vowel, the reasons for the preservation of a «strong» $-r$, which additionally would play no visible grammatical role, escape me. 
needless to say, there are no reliable data about its actual phonetic realisation in this particular context, in which voicedness is disfavoured ${ }^{83}$.

e) The sequence ${ }^{*}$-r.s-, whether original or secondary, tends to assimilation, regressive or progressive, or deletion of the rhotic.

In Umbrian, a post-syncope cluster -r.z- did not undergo rhotacism. It merged with the outcome of IE*-r.s-, which in turn shows a tendency to simplification to judge by the spelling hesitation in ${ }^{*}$ tors $\bar{a}>$ divine name U. turse, tuse, etc. ${ }^{84}$ In sum, it never underwent excrescence, since no factor favoured it. In point of fact, stop excrescence in this context, by which *-r.syields ${ }^{*} r^{t} s^{-}$, is very uncommon, although sporadic cases are reported ${ }^{85}$. Conversely, while an evolution ${ }^{*}-s n->-s^{t} n$ - is less common than ${ }^{*}-n s->-n^{t} s-$, every Indo-Europeanist knows a sizable number of cases of ${ }^{*}-s r->-s^{t} r-$, given the stronger realisation of the rhotic in -s.r- (with a trill [r] unless epenthesis occurs, e. $g .-s^{d / t} r-$ or $-s^{a} r-$ ) than in $-r . s-$ (with a tap [r]). This indicates that our only plausible example of this phenomenon, U. trahuorfi 'transverse' (<*-urrtsto-; Um 1 VIIa 25), had a segmental $/ \mathrm{t} /$, which would in turn mean that ${ }^{*}-n / r^{s} t$ - directly yielded Sabellic $-n / r t s s-$, as contended immediately above (5.3., 6.).

Accordingly, since ${ }^{*}-r . s->^{*}-r^{t} s-$ is infrequent (and ${ }^{*}-r . z^{-}>^{*}-r^{d} z$ - nonexistent, see fn. 49 above), the last argument that could be reasonably invoked to rescue the validity of the change ${ }^{*}-r V s^{-}>^{*}-r . s / z-{ }^{*}-r f-$ vanishes. In a nutshell, the traditional etymologies of parfa and çerfe have been underpinning each other, but both lack comparative support and phonetic plausibility. What is more, they have been instrumental in sacrificing the self-evident cognacy of the outcomes of the Italic divine epithet *keres-iio-.

In Oscan, as in Latin, ${ }^{*}-r . z$ - underwent progressive assimilation and became $-r r-$. This allows us to place our three major dialects at two different stages of the natural evolution * $r V z$ (Italic) $>^{*}-r z-\left(>-r s-\right.$, Umbrian) $>-r r-\left(\right.$ Oscan, Latin $\left.{ }^{86}\right)$.

As regards the outcome of Sabellic ${ }^{*}-n V s \#$ and ${ }^{*}-r V s \#$ after final vowel syncope, the first sequence yields Oscan and Umbrian $-n s$, also in the secondary $3^{\text {rd }}$ pl. ending (in all likelihood remodeled after the $1^{\text {st }} \mathrm{pl}$. ending ${ }^{*}-m e s>-m s$ ), and the second $-\bar{V} r$ (nom. pl. $-\bar{e} r$ in O. ${ }^{*} n e e r$, U. frater). Venetic - $r V s$ undergoes syncope at least in trisyllabic forms, as in *teuteros $>$ te.u.te.r.s. (Padua, cf. Prósper 2018c) ${ }^{87}$.

${ }^{83}$ This change has a parallel in Hittite, where only particular sequences of the form -ns-, -ms-, -rs- undergo epenthesis: *nsós ><an-za-a-aš> 'us' (gen.), * $h_{2}$ msosio- $><a-a n-z a-a-a s ̌-s ̌ a->$ 'descendant', besides forms in which these segments were separated by a laryngeal, as in *'gen $h_{1} s u-><g e-e n-z u>$ 'lap, womb', or in the nom. sg. in -r- + -s, as in * $h_{2} s t e \bar{r}-s<h a-a \check{S}^{-}$ te-er-za> 'star' (see EDHIL: 70-74). In Tocharian, this change might have occurred in intervocalic position only after syncope, judging by ${ }^{B}$ Toch. āntse 'shoulder' (if < ${ }^{*} h_{2} \mathrm{OmVso}$-) but AToch. es, kentse 'rust' (if < ${ }^{*}$ koniso-), intsu 'which, what kind of (<*heno- $+s V-)$, ontsoytte 'insatiable' (a compound of privative $\left.{ }^{*} n_{0}+s V-\right)$, kwants 'firm' (if < *kuneso-, cf. DTB: passim).

${ }^{84}$ This is in fact the most common evolution for this cluster across languages: see Recasens (2018: 177-178).

${ }^{85}$ Epenthesis [rs] > [rts] is reported to happen in the Romansch dialect of Bergün (Switzerland) and in central and southern Italian dialects (Old Romanesco perzona 'persona', Calabrian vurza 'borsa', etc.). Cf. Rohlfs (1968: 381). It is sporadically attested elsewhere in particularly difficult clusters, for instance in AToch. kursär 'mile, vehicle', obl. pl. kursärwä/kurtsru; in a couple of cases in Old Languedocian (the singular forms chartz, cavalliertz, cf. Chabaneau 1879, who considers these two forms as scribal errors, as opposed to comparatively more widespread $-<n t z>$, $-<l t z>$ ); and in some Modern Greek dialects like Pontic (cf. Moutsos 1976). Even sporadic epenthesis in this particular context always presupposes comparatively regular epenthesis in /ns/ and /ls/, suggesting it is more unnatural. In the conclusions of his study of epenthesis in /ns/ and /ls/ in a Catalan dialect, Recasens (2012: 88), observes that «the failure for /rs/ to undergo stop insertion and to exhibit a well-defined burst may be attributed to a weak closure resulting from the antagonistic manner requirements involved in the performance of the tongue tip vibration for a syllable final trill and the generation of audible turbulence for the lingual fricative».

${ }^{86}$ If and only if the regular phonetic outcome presupposes syncope, that is to say if L. ferre 'bring' is from ${ }^{*} b^{h}$ eresi and Cereri, by contrast, has reinserted the medial vowel.

${ }^{87}$ Interestingly, the Etruscan divine name Fufluns, in all likelihood an inherited adjective in *-ōno- of Sabellic origin (cf. Meiser 1986: 215) is occasionally attested as Fuflunz, reflecting a pronunciation [nts]. 
f) This change a fortiori never affected IE *-Vn.s-, nor *-Vr.s-. The often repeated assumption that IE ${ }^{*}-V n . s V$ - becomes Proto-Sabellic ${ }^{*}-V n^{t} s V$ - has no basis, and for all we know it may have passed to $-\bar{V} s V$ - early on. As we have just seen, ${ }^{*}-V r$.s- is preserved in Umbrian (possibly with voicing of the sibilant, which at any rate never underwent rhotacism), but yielded $-\bar{V} r$ - in Oscan and -Vrr-in Latin. Again, this places our major dialects at three different stages of the evolution ${ }^{*}-V r s V-\left(\right.$ Umbrian) $>{ }^{*}-V r z V->{ }^{*}-V r \hbar V->{ }^{*}-V r r V-$ (Latin) $>{ }^{*}-\bar{V} r V-$ (Oscan), which may have started independently or may have spread as an areal feature.

\section{APPENDIX. Observations on the Pre-Samnite vase of Niumsis Tanunis}

The recently uncovered «Opic» or «Pre-Samnite» vase of Niumsis Tanunis dates from the end of the $5^{\text {th }}$ or beginnings of the $4^{\text {th }} \mathrm{C}$. BC, hails from somewhere in Campania and is conducted in the Oscan national alphabet (see Agostiniani et al. 2012). Face A reads: Niumsies Tanunies est ('(it) belongs to Niumsis Tanunis'). Face B reads: ?paplamtensatriiam fufuhud niumsis tanunis eises ulsu dunum dedum (conducted in scriptio continua).

Martzloff (2017) has recently offered several alternative analyses of <paplamtensatriiam> at the beginning of face B (in fact the only sequence of controversial segmentation). He pays heed to the possibility, suggested by the editors, that the right division is $\langle$ paplam tens atriiam $\rangle$, meaning 'close to papla atria' or 'for papla atria'. In turn, 'papla atria' is to be explained either as the recipient of the vase 'for Papla Atria' (in which tens goes back to a preposition *tenos, cf. L. tenus) or as the vase itself (papla) that is a present for a woman called Atria ${ }^{88}$.

Martzloff alternatively reckons with a more convincing segmentation <paplam tensatriiam>. This provides a DO for the following Vfufuhud SNiumsis Tanunis 'Niumsis Tanunis has made', which has been topicalised and attracted to the beginning of the sentence. Martzloff offers no compelling account of the word formation. In my view, however, it paves the way for a connection with U. tenzitim/TESEDI (acc. sg., Um $1 \mathrm{Ib}$ 6; VIb 46), a hitherto uninterpreted form designating something one has to bring out at some moment of the ritual, and, in view of the voiced segment $\langle\mathrm{D}>$, perhaps going back to *tenes-not-iio- or *tenes-e-ent-iio-. If these forms are related at all and designate something in the sphere of pots or vessels, they must contain a stem *ten-Vs-.

The first cognate that comes to mind is L. tenōr 'course', tenus 'snare' and compounds like

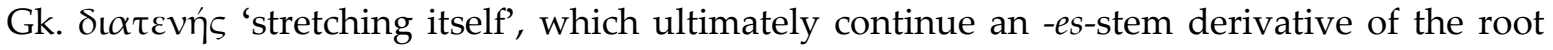
*ten- 'stretch'. If we start from a denominative stem *tenes $\bar{a}-$, the «Opic» form can reflect an adjective *tenes $\bar{a}-t r-i i o-$, derived from an instrument noun in $-\bar{a}-t r o-$ (cf. the similar derivational history of $\bar{r} \bar{r}$ culum). The meaning is not clear, but 'preserver' or simply 'container, tray' (L. tenere, con-tinere, U. tenitu 'let him hold' belong to the same root) are conceivable. It could also mean 'portable' in view of the description given by the editors, who explain the holes in the grips as designed so that the skyphos could be held and carried by a temporarily fitted handle. Its formation is thus roughly comparable to that of L. tenāculum 'holder' > 'tongs'.

Neither tensatriiam nor Niumsis (in all likelihood an Oscan name) show post-syncope epenthesis, at least not in writing. From a slightly different angle, the denominative verb could be derived from the past participle of L. tendō 'stretch', U. ustetu/OSTENDV ( $3^{\text {rd }}$ p. sg. fut. impv.,

${ }^{88}$ Triantafillis (2014) has contributed a new interpretation of paplam as 'teat-shaped vase', which is retained as correct in the following lines. Her own translation 'has poured a substance (atria) into the papla', however, has no parallels and her analysis of fufuhud as a perfect form of the root ${ }^{*} g^{h} \mathrm{eu}$ - (with $f$ - for $h$-) is unwarranted, as observed by Martzloff. 
Um 1 passim) 'prepare, show, exhibit?', like L. *tēnsāre, not directly attested but preserved in most Romance dialects. L. tênsa is a kind of chariot for the exhibition of the exuviae deorum, a still unclear ritual performance. Apparently, instrument nouns built to different enlarged variants of the root ${ }^{*} t e n$ - gained considerable productivity in Italic. While this must remain merely speculative, if we accept that paplam refers to the vase itself, it could be argued that it literally means "instrument/container of nurture", and that it goes back to a collective form ${ }^{*} p h_{2}-d^{h} l e h_{2}$, which would have regularly given * $p \bar{a} \beta l \bar{a}$ and then * $p \bar{a} p l \bar{a}$ by sporadic assimilation of labials or a scribal perseverative error. In turn, this error could be favoured by the fact that several words in this text contain the same consonant in consecutive syllables and still more understandable if the scribe was actually copying from a written model. This form could then be ultimately identical to L. päbulum 'sustenance'.

The interpretation of the verb form and the various syntactic possibilities compatible with it are problematic, too. In view of their superficial resemblance, fufuhud has been taken to be identical to fufuFoo (Tortora), with $<h>$ marking the hiatus, a device attested in Oscan, and to mean 'has/have been' (Agostiniani et al. 2012: 138). This idea looks formally attractive but is at odds with a number of facts. Firstly, it is not certain that $/ \mathrm{h} / \mathrm{was}$ no longer realised at that time, and that the letter used for the aspiration could now be put to service in this way or to mark vowel length, as in the rest of Sabellic. Secondly, this is not exactly like other hiatuses: it must have contained a transitional [u] that would probably be represented in a different manner, as in Tortora ${ }^{89}$. Thirdly, the preceding accusative paplam tensatriiam requires a transitive verb. Finally, if we interpreted tens as a preposition, as Agostiniani et al. (2012) have done, we would hardly expect it to govern an accusative of direction with the verb 'to be'. Martzloff (2017: 140) tentatively reconstructs ${ }^{*} d^{h} e-d^{h} O i g_{-}{ }_{-}$'has fashioned, modeled'. A sound change /oi/ > /u:/ would be underpinned by South-Picene persukant, if from *soik- (as per Meiser 1986: 88). Note, however, that this attractive etymology is exclusively based on Umbrian forms of the same root: the $3^{\text {rd }}$ pers. pl. fut. perf. prusikurent 'confirm, declare', traced back to *seik-, and, crucially, the fut. impv. sukatu, which Meiser traces back to a denominative verb ${ }^{*}$ soik $\bar{a}$ (in turn the only instance of the alleged sound change /oi / > /u:/ in Umbrian). All these forms, however, are generally traced back to *sek"- 'say' (LIV: 526). Cf. WOU: 712, Weiss (2010: 187, fn. 164). The change /oi/ > / u:/ is borne out by a single form but is proposed for two languages, whose testimonies underpin each other. Consequently, the hypothesis, however seductive at first sight, incurs circularity and remains unproven. There is, in addition, a minor problem of pragmatic redundancy: it is somewhat outlandish that Face A states that the object belongs to Niumsis Tanunis (Niumsies Tanunies est) and Face B that he is the artisan who has actually created it.

The possible objections against the assumed shift and the reconstruction of two different Sabellic preterites may be bypassed by the alternative postulation of a perfect ${ }^{*} d^{h} e-d^{h} u g^{h}-$ 'has

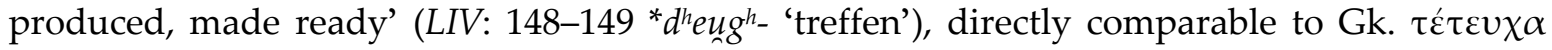
'have produced', and possibly Mycenaean n. pl. te-tu-ko-wo-a 'prepared, set up', $\tau \varepsilon \tau \varepsilon v \chi \omega \varsigma$ 'wrought', which can be taken to mean that this perfect was originally stative. Crucially, this verb would have merged in Italic in a number of forms with the outcome of *beug-, as in L. fungor, which may have favoured its eventual disappearance. Under these premises, the reduplication vowel / $\mathrm{u}$ / is straightforwardly accounted for, as in Vedic dudóha 'has milked'. In ad-

${ }^{89}$ If Willi (2010) is right and Italic inherited a perfect ${ }^{*} b^{h} u-b^{h} u-e(-i)>{ }^{*} f u \beta u e i$, which somewhere down the line became opaque and was dialectally recharacterised by a new reduplication, the underlying approximant would hardly be expected to be spelt $\langle h\rangle$. On the other hand, SP. súhúh $<{ }^{*}$ soūōd (TE $1, \mathrm{~S}$. Omero) does not qualify as a counterexample. According to Weiss (2002: 356-357), [u] was lost in this context and $<h>$ notes the subsequent raising of the first $/ \mathrm{o} /$. 
dition, this sets the stage for an alternative syntactic analysis: tensatriiam could be not the determinans of paplam, but a predicative complement. A very tentative translation would then run: 'Niumsis Tanunis has made the papla as / to serve as, play the role of [---]' 90 .

Additionally, we have an interesting sequence eises $u l s u$ in the same text, immediately following fufuhud Niumsis Tanunis. In line with former interpretations, I translate 'eius iussu', 'by his will', vel sim. The first form is in all likelihood the gen. sg. masc. of an anaphoric pronoun, and the second is an ablative or instrumental singular and has been given a number of etymological interpretations without foothold in Italic itself (see Martzloff 2017, with references). As observed by Agostiniani et al. (2012: 136), the actual form may actually have been ulsud, with the habitual omission of the final consonant when the next word begins by the same one.

I trace $u l s u(d)$ to a thematic derivative * ${ }_{o} l H t i-\bar{o}(d)$ of the action noun *ullHti- 'power; will'. Its base is thus equatable to OIr. flaith 'sovereignty' and the first member of the Venetic personal names vo.l.tigno.s., voltigenei ( $L V: 63,56$, Este). Interestingly, Euganean Venetic is characterised by a similar formula closing a number of inscription: o.p. vo.l.tiio leno 'by free/sovereign will/power' ( $L V: 12 \mathrm{~A}$, Este, translated in 12B as [D]O[NOM] DEDIT LIBENS MERITO). Thus, ulsu(d) and vo.l.tiio ${ }^{91}$ are identical forms that occurred exactly in the same context: $u l s u(d)$ is immediately followed by the formula dunum dedum 'I gave as a gift', which closes the text. Palatalisation, subsequent affrication and perhaps eventual fricativisation of -ti- were probably only possible at such an early date for a Proto-Italic sequence *-tiV-, not *-tii $V$-, and the actual phonetic realisation may have been closer to $[\mathrm{ts}]^{92}$. We would consequently expect $+u$ olsu. The spelling $u l$ - can be due to assimilation *uv- $>{ }^{*} u u$ - and ensuing reduction or simply graphic omission of $/ \mathbf{u} /{ }^{93}$. Either $u l s u(d)$ was substantivised or the expression was reproduced in abbreviated form, but at any rate eises $u l s u(d)$ looks like a very old formula ${ }^{94}$. The destinatary of the vase might have been a person, a divinity or a group of them, which would have been left unmentioned; face B could mean something like 'the vase ?... made Niumsis Tanunis; in fulfilment of his will, I gave it as a gift'. The subject of the enunciation and of the sentence 'I gave' is the person who, ex hypothesi, fulfilled the vow of the deceased Niumsis Tanunis or placed it in his tomb to ensure him a safe journey to the underworld.

\section{References}

Adams, James Noel. 2013. Social Variation and the Latin Language. Cambridge University Press. Agostiniani, Luciano, Giulio M. Facchetti. 2012. Il vaso di Niumsis Tanunis. Studi Etruschi 75: $123-146$. Akamatsu, Tsutomu. 2011. Epenthetic plosives in English: phonetic and phonological aspects. Moenia 17: 87-124.

${ }^{90}$ Under a still more daring assumption, which is little more than a guess, one could ascribe to the root * $d^{h}$ eug $g^{h}$ - an ancient meaning 'to milk' which is hitherto only known from Indo-Arian. Since paplam has been associated to L. papilla and taken to mean 'breast vase', which must be a metaphorical designation in view of the shape of the vase (see Triantafillis 2014; Martzloff 2017) this could be a cheerful way of celebrating Niumsis' main hobby: 'has milked the breast ...' would simply be a humorous allusion to drinking wine.

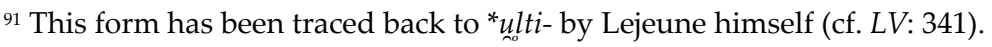

${ }^{92} \mathrm{Cf}$. the Italic personal names VOLSO, VOLSONI attested in Dalmatia and Venetia et Histria; vOLSA in Samnium and Picenum, VOLSARIA in Venetia et Histria, and, for the latter coalescence, BANSAE for tBANTIAE (Lu 1, 100 BC). Bear in mind that LECIONIBVS MARTSES (CIL I: 5, Luco dei Marsi, from * martiio-) is already attested in the $4^{\text {th }}$ C. BC.

93 The root-final laryngeal was in my view lost in this position early in Italic, as shown by all the extant cognates of this root (cf. Prósper 2017).

${ }^{94}$ Needless to say, this sets the stage for the possibility of tracing tensatriiam to *ten-ti-ā-tro-, with palatalisa-

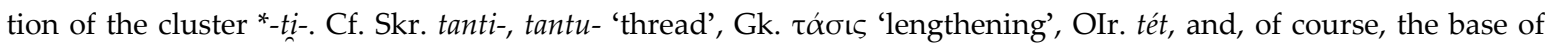
Latin compounds like con-tentiō. 
Alonso Déniz, Alcorac. 2011. El supuesto alargamiento compensatorio * $\pi \dot{\varepsilon} v \sigma \mu \alpha>\pi \varepsilon \tilde{\imath} \sigma \mu \alpha$ 'amarre, cuerda' en griego antiguo y otras cuestiones relacionadas. Die Sprache 49: 217-253.

Bader, Françoise. 1962. La formation des composés nominaux du latin. Paris: Les Belles Lettres.

Beekes, Robert S. P. 1982. GAv. må. The PIE Word for Month, Moon and the Perfect Participle. The Journal of IndoEuropean Studies 10: 53-63.

Beekes, Robert S. P. 2010. Etymological Dictionary of Greek. Vols. 1-2. Leiden / Boston: Brill.

Beltrán Lloris, Francisco, Jürgen Untermann, Javier De Hoz. 1996. El tercer bronce de Botorrita (Contrebia Belaisca). Zaragoza: Institución Fernando el Católico.

Benediktsson, Hreinn. 1960. The Vowel Syncope in Oscan-Umbrian. Norsk Tidsskrift for Sprokvidenskap 19: 157-295.

Bonfante, Giuliano. 1988. Venètico, itàlico, latino. In: P. Kosta, G. Lerch, P. Olivier (eds.): Festgabe Werner Thomas zum 65. Geburtstag: 9-12. Munich: Segner.

Bottiglioni, Gino. 1954. Manuale dei dialetti italici: osco, umbro e dialetti minori. Bologna: STEB.

Buck, Carl D. 1904. A Grammar of Oscan and Umbrian. With a Collection of Inscriptions and a Glossary. Boston: Ginn and Co.

Burroni, Francesco. 2016. A Tale of two Roots: PIE *kerh ${ }_{1 / 3^{-}}$, PIE *(s)ker-, and the Umbrian Month Name çersiā-. Talk given at the 28th Annual UCLA Indo-European Conference, November 11th and 12th, 2016. Available online at: https://pies.ucla.edu/IEConference/IECabstracts/burroni_f_2016.pdf.

Chabaneau, Camille. 1879. T non-étymologique en Langue d’Oc. Romania 8: 110-114.

Clackson, James. 2013. Subgrouping in the Sabellian Branch of Indo-European. Transactions of the Philological Society 111: 4-37.

Coseriu, Eugenio. 1966. Tomo y me voy. Ein Problem vergleichender europäischer Syntax. Vox Romanica 25: 13-55.

Cowgill, Warren. 1980. The Etymology of Ir. guidid and the Outcome of IE ${ }^{*} g^{w} h$ in Celtic. In: M. Mayrhofer, M. Peters, O. Pfeiffer (eds.). Lautgeschichte und Etymologie. Akten der VI Fachtagung der Indogermanischen Gesellschaft: 49-78. Wiesbaden: Reichert.

Cser, András. 2012. The Role of Sonority in the Phonology of Latin. In: S. Parker (ed.). The Sonority Controversy: 3953. Berlin: De Gruyter.

Derksen, Rick. 2007. Etymological Dictionary of the Slavic Inherited Lexicon. Leiden: Brill.

DTB = Adams, Douglas Q. 1999. A dictionary of Tocharian B. Amsterdam: Rodopi.

Dupraz, Emmanuel. 2012. Sabellian Demonstratives: Forms and Functions. Leiden: Brill.

EDHIL $=$ Kloekhorst, Alwin. 2008. Etymological Dictionary of the Hittite Inherited Lexicon. Leiden: Brill.

EDLIL = De Vaan, Michiel. 2008. Etymological dictionary of Latin and the other Italic languages. Leiden: Brill.

Fisher, Jay. 2014. The Annals of Quintus Ennius and the Italic Tradition. Baltimore: Johns Hopkins University Press.

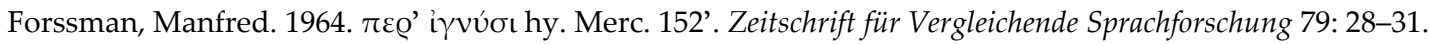

Fortson, Benjamin W. 2017. The Dialectology of Italic. In: J. Klein, B. Joseph, M. Fritz (eds.). Handbook of Comparative and Historical Indo-European Linguistics II: 835-857. Berlin / Boston: De Gruyter Mouton.

Fortson, Benjamin W., Michael Weiss. 2019. Oscan kúnsíf deívúts and the Dì Consentes. Classical Philology 114: 637-645.

Fourakis, Marios, Robert Port. 1986, Stop Epenthesis in English. Journal of Phonetics 14: 197-221.

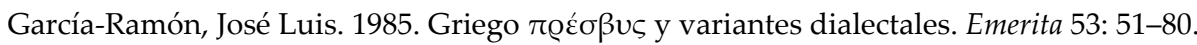

Gualtieri, Maurizio, Paolo Poccetti. 2001. Frammento di tabula bronzea con iscrizione osca dal pianoro centrale. In: M. Gualtieri, H. Fracchia (eds.). Roccagloriosa II. L'oppidum lucano e il territorio: 187-274. Naples: Centre Jean Bérard.

Hamp, Eric P. 1972. On Medial s in Italic. Glotta 50: 290-291.

Hansen, Peter A. (ed.). 2005. Hesychii Alexandrini Lexicon. Volumen III. П- $\Sigma$. Berlin / New York: Walter de Gruyter.

Hill, Eugen. 2003. Untersuchungen zum inneren Sandhi des Indogermanischen: der Zusammenstoss von Dentalplosiven im Indoiranischen, Germanishen, Italischen und Keltischen. Bremen: Hempen Verlag.

Höfler, Stefan. 2017. Observations on the palma-Rule. Pallas 103: 15-23.

Höfler, Stefan. 2018. A Look over L. umerus 'Shoulder'. In: D. M. Goldstein, S. W. Jamison, B. Vine (eds.). Proceedings of the 29th Annual UCLA Indo-European Conference: 129-146. Bremen: Hempen Verlag.

IItal. = Crawford, Michael H. et al. (ed.). 2011. Imagines Italicae: A Corpus of Italic Inscriptions I-III. Bulletin of the Institute of Classical Studies Supplement 110. University of London.

Kavitskaya, Darya. 2002. Compensatory Lengthening. Phonetics, Phonology, Diachrony. London / New York: Routledge.

Klingenschmitt, Gert. 1992. Die lateinische Nominalflexion. In: O. Panagl, Th. Krisch (eds.). Latein und Indogermanisch: Akten des Kolloquiums der Indogermanischen Gesellschaft, Salzburg, 23-26 September 1986: 89-135. Innsbruck: IBS. 
Koch, Christoph. 1990. Das morphologische System des altkirchenslavischen Verbums I-II. Munich: W. Fink.

Koch, John T. 1992. Gallo-Brittonic Tasc(i)ouanos «Badger-slayer» and the Reflex of Indo-European gwh'. Journal of Celtic Linguistics 1: 101-118.

La Regina, Adriano. 2017. Tegola con iscrizione osca. In: A. G. Pezzi, M. C. Rossi (eds.). San Giovanni in Venere. Storia, arte e archeologia di una abbazia benedittina. 109-110. Pescara: Carsa.

Lazzarini, Maria L., Paolo Poccetti. 2001. Il mondo enotrio tra VI e V secolo a. C. Atti dei seminari napoletani (19961998), L'iscrizione paleoitalica da Tortora. Naples: Loffredo.

Lejeune, Michel. 1970. Phonologie osque et graphie grecque. Revue des Études Anciennes 72: 271-316.

LIV = Rix, Helmut, Martin Kümmel et al. 2001. Lexicon der indogermanischen Verben. Die Wurzeln und ihre Primärstammbildungen. Wiesbaden: Reichert.

LV = Lejeune, Michel. 1974. Manuel de la langue venète. Heidelberg: Carl Winter Universitätsverlag.

Marinetti, Anna. 1985. Le iscrizioni sudpicene. I. Testi. Florence: Leo Olschki Editore.

Marinetti, Anna, Aldo L. Prosdocimi. 1994. Nuovi ciottoloni venetici iscritti da Padova paleoveneta. In: B. M. Scarfi (ed.). Studi di archeologia della X regio in ricordo di Michele Tombolani: 171-192. Rome: L'Erma di Bretschneider.

Martzloff, Vincent. 2017. A propos des formes opiques paplam, dedum, fufuhud (inscription de Niumsis Tanunis). Wek ${ }^{w}$ OS 3: 117-148.

McDonald, Katherine, Nicholas Zair. 2012. Oscan Fov@ovot and the Roccagloriosa Law Tablet. Incontri Linguistici 35: 31-45.

Meiser, Gerhard. 1986. Lautgeschichte der umbrischen Sprache. Innsbruck: Innsbrucker Beiträge zur Sprachwissenschaft.

Meiser, Gerhard. 1987. Pälignisch, Latein und Südpikenisch. Glotta 65: 104-125.

Méndez Dosuna, Julián V. 1994. Contactos silábicos y procesos de geminación en griego antiguo. A propósito de

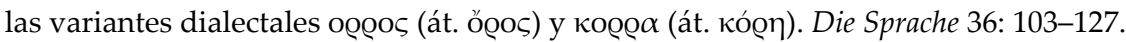

Méndez Dosuna, Julián V. 1996. Can Weakening Processes Start in Initial Position? The Case of Aspiration of /s/ and /f/. In: B. Hurch, R. A. Rhodes (eds.)., Natural Phonology. The State of the Art: 97-106. Berlin / New York: De Gruyter.

Méndez Dosuna, Julián V. 2007. Ex praesente lux. In: I. Hajnal (ed.). Die altgriechischen Dialekte, Wesen und Werden: 355-384. Innsbruck: IBS.

Mihaylova, Biliana. 2016. The Pre-Greek Substratum Revisited. In: B. Simmelkjær, S. Hansen, B. Nielsen Whitehead, Th. Olander, B. A. Olsen (eds.). Etymology and the European Lexicon. Proceedings of the 14th Fachtagung der Indogermanischen Gesellschaft: 307-317. Wiesbaden: Reichert.

Mommsen, Theodor. 1846. I. Bronzo di Rapino. Annali dellinstituto di Corrispondenza Archeologica: 82-98.

Moutsos, Demetrios. 1976. Some Observations on a Phonological Problem of Middle and Modern Greek. Zeitschrift für vergleichende Sprachforschung 89: 235-264.

Naïm, Samia. 2016. On Interaction between External and Internal Markers in Expressing Aspect in Arabic Dialect Varieties. In: Z. Guentchéva (ed.). Aspectuality and Temporality. Descriptive and Theoretical Analyses: 325-354. Amsterdam / Philadelphia: John Benjamins Publishing Company.

Neri, Sergio. 2012. Zum indogermanischen Wort für 'hand'. In: A. Cooper, J. Rau, M. Weiss (eds.). Multi Nominis Grammaticus. Studies in Classical and Indo-European Linguistics in Honor of Alan J. Nussbaum on the Occasion of his 65th Birthday: 185-205. Ann Arbor / New York: Beech Stave Press.

Neri, Sergio. 2019. Riflessi delle laringali indoeuropee in germanico. In: R. Roselli (ed.). Dall' indoeuropeo al germanico: Problemi di Linguistica storica: 41-66. Alessandria: Edizioni dell'Orso.

Nussbaum, Alan J. 1986. Head and Horn in Indo-European. Berlin / New York: De Gruyter.

Ohala, John J. 1974. Experimental Historical Phonology. In: J. M. Anderson, Ch. Jones (eds.). Historical Linguistics, II: Theory and Description in Phonology: 353-389. Amsterdam: North-Holland.

Ohala, John J. 1997. Emergent Stops: Diachronic and Phonetic Data. Proceedings of Seoul International Conference on Linguistics: 307-317. Seoul: Linguistic Society of Korea.

Ohala, John J., M. Grazia Busà. 1995. Nasal Loss before Voiceless Fricatives: a Perceptually-based Sound Change. Rivista di Linguistica 7: 125-144.

Peters, Martin. 1980. Untersuchungen zur Vertretung der indogermanischen Laryngale im Griechischen. Wien: Österreichische Akademie der Wissenschaften.

Pisani, Vittore. 1953. Le lingue dell'Italia antica oltre il Latino. Torino: Rosenberg \& Sellier.

Poccetti, Paolo. 2006. Notes de linguistique italique 3. L'attestation osque du nom pour «consul» et le traitement de [ns] avec ses reflets latins et romans. Revue des Études Latines 84: 27-36. 
Poccetti, Paolo. 2009. Problemi antichi e dati nuovi: Coincidenze di teonimi e di antroponimi nell'italia antica. In: P. Poccetti (ed.). L'onomastica dell'Italia antica. Aspetti linguistici, storici, culturali, tipologici e classificatori: 219248. Rome: École Française de Rome.

Poccetti, Paolo. 2013. Eine neue kalendarische Angabe im Oskischen mit einem Exkurs über den Vornamen Minis. Linguarum Varietas 2: 207-222.

Poccetti, Paolo. 2013b. Notes de linguistique italique: 13. De nouveaux théonymes osques et leur relation avec les divinités romaines. Revue des Études Latines 91: 27-46.

Poccetti, Paolo. 2016. The Italic Words for «Moon/Month» and «Sun». New Evidence from the Sabellian Languages. In: B. Simmelkjær, S. Hansen, B. Nielsen Whitehead, Th. Olander, B. A. Olsen (eds.). Etymology and the European Lexicon. Proceedings of the 14th Fachtagung der Indogermanischen Gesellschaft: 353-363. Wiesbaden: Reichert.

Prosdocimi, Aldo L. 1996. La Tavola di Agnone. Una interpretazione. In: L. Del Tutto Palma (ed.). La Tavola di Agnone nel Contesto Italico: 435-630. Firenze: Cosmo Iannone.

Prósper, Blanca María. 2017. Proto-Italic Laryngeals in the Context ClHC- and New Italic and Celtic Etymological Connections. Rivista Italiana di Linguistica e Dialettologia 19: 1-24.

Prósper, Blanca María. 2018a. The Indo-European Personal Names of Pannonia, Noricum and Northern Italy: Comparative and Superlative Forms in Celtic, Venetic, and South-Picene. Voprosy Onomastiki 15: 108-138.

Prósper, Blanca María. 2018b. The Venetic Agent Nouns in -tōr- Revisited. In: J. M. Vallejo, I. Igartua, C. G. Castillero (eds.). Studia Philologica et Diachronica in Honorem Joaquín Gorrochategui: 453-471. Vitoria: Publicaciones de la Universidad del País Vasco.

Prósper, Blanca María. 2018c. The Venetic Inscription from Monte Manicola and three termini publici from Padua: A Reappraisal. The Journal of Indo-European Studies 46: 1-61.

Prósper, Blanca María. 2019a. Celtic and Venetic in Contact: The Dialectal Attribution of the Personal Names in the Venetic Record. Zeitschrift für Celtische Philologie 66: 7-52.

Prósper, Blanca María. 2019b. Language Change at the Crossroads: what Celtic, what Venetic, and what else in the Personal Names of Emona? Voprosy Onomastiki 16: 33-73.

Prósper, Blanca María. 2020. Mars Veneticus and the Palma Rule. Ms. (to appear in a Festschrift).

Rasmussen, Jensgard E. 1994. Ablaut zwischen Konsonanten: Die Quellen von Idg. /s/. In: G. Dunkel et al. (eds.). Früh-, Mittel-, Spätindogermanisch. Akten der IX Fachtagung der Indogermanischen Gesellschaft: 325-336. Wiesbaden: Reichert.

Recasens, Daniel. 2012. The Phonetic Implementation of Underlying and Epenthetic Stops in Word Final Clusters in Valencian Catalan. Journal of the International Phonetic Association 42: 65-90.

Recasens, Daniel. 2018. The Production of Consonant Clusters. Implications for Phonology and Sound-change. Berlin / New York: Mouton-De Gruyter.

Repetti, Lori. 2002. Non-homorganic Nasal Clusters in Northern Italian Dialects. In: T. Satterfield, Ch. Tortora, D. Cresti (eds.). Current Issues in Romance Languages, Selected papers from the 29th Linguistic Symposium on Romance Languages (LSRL), Ann Arbor, 8-11 April 1999: 271-285. Amsterdam / Philadelphia: Benjamins.

Rix, Helmut. 1986. Die Endung des Akkusativ Plural Commune im Oskischen. In: A. Etter (ed.). O-o-pe-ro-si. Festschrift für Ernst Risch zum 75. Geburtstag: 583-597. Berlin / New York: De Gruyter.

Rix, Helmut. 1993. Osk. upsannam - uupsens und Zugehöriges. In: F. Heidermanns, H. Rix, E. Seebold (eds.). Sprachen und Schriften des antiken Mittelmeerraums: Festschrift für Jürgen Untermann: 329-348. Innsbruck: Innsbrucker Beiträge zur Sprachwissenschaft.

Rix, Helmut. 1994. Latein und Sabellisch. Stammbaum oder Sprachbund? Incontri Linguistici 17: 13-29.

Rix, Helmut. 1998. Eine neue frühsabellische Inschrift und der altitalische Präventiv. Historische Sprachforschung 111: 247-269.

Rocca, Giovanna. 1996. Ancora sul dossier italico di Cerere. In: L. Del Tutto Palma (ed.). La Tavola di Agnone nel Contesto Italico: 645-660. Firenze: Cosmo Iannone.

Rohlfs, Gerhard. 1968. Grammatica storica della lingua italiana e dei suoi dialetti. Turin: Einaudi.

Ruijgh, Cornelis J. 1967. Études sur la grammaire et le vocabulaire du grec mycénien. Amsterdam: Hakkert.

Schumacher, Stefan. 2004. Die keltischen Primärverben. Ein vergleichendes, etymologisches und morphologisches Lexikon. Innsbruck: Innsbrucker Beiträge zur Sprachwissenschaft.

Schumacher, Stefan, Joachim Matzinger. 2013. Die Verben des Altalbanischen. Wiesbaden: Harrassowitz.

Segenni, Simonetta. 2007. Mesene Flusare. Nota sulla provenienza vestina (e non sabina) dell iscrizione Vetter 227. Epigraphica 69: 389-395. 
Simon, Zsolt. 2020. The Anatolian Stop-system and the Indo-Hittite Hypothesis - Revisited. In: M. Serangeli, Th. Olander (eds.). Dispersals and Diversification: Linguistic and Archaeological Perspectives on the Early Stages of Indo-European: 236-250. Leiden / Boston: Brill.

Solmsen, Felix. 1907. Weiteres zum Suffix -áoıv. Rheinisches Museum für Philologie, Neue Folge 62: 636-638.

ST = Rix, Helmut. 2002. Sabellische Texte. Die Texte des Oskischen, Umbrischen und Südpikenischen. Heidelberg: Carl Winter Universitätsverlag.

Stefanowitsch, Anatol. 2000. The English GO-(PRT)-AND-VERB Construction. In: Lisa J. Conathan (ed.). Proceedings of the Twenty-Sixth Annual Meeting of the Berkeley Linguistics Society: General Session and Parasession on Aspect: 259-270. Berkeley Linguistics Society.

Stuart-Smith, Jane. 2004. Phonetics and Philology. Sound Change in Italic. Oxford University Press.

Tikkanen, Karin W. 2011. A Sabellian case grammar. Heidelberg: Carl Winter Universitätsverlag.

Tocco, Giuliana. 2000. Frammento di legge in lingua osca su tavola bronzea. In: A. La Regina (ed.). Studi sull' Italia dei Sanniti: 224-229. Milan: Electa.

Triantafillis, Elena. 2014. Osservazioni sull'iscrizione italica di Niumsis Tanunis: tra ermeneutica e linguistica. Padua Working Papers in Linguistics 6: 3-44.

Untermann, Jürgen. 1968. Merkmale der Wortgrenze in den Altitalischen Sprachen. Word 24: 479-490.

Vaux, Bert. 1998. The Laryngeal Specifications of Fricatives. Linguistic Inquiry 29: 497-511.

Vetter, Emil. 1953. Handbuch der italischen Dialekte, I. Band. Texte mit Erklärung, Glossen, Wörterverzeichnis. Heidelberg: Carl Winter Universitätsverlag.

Vine, Brent. 1993. Studies in Archaic Latin Inscriptions. Innsbruck: Innsbrucker Beiträge zur Sprachwissenschaft.

Vine, Brent. 2016. Latin crassus, grossus, classis. Indogermanische Forschungen 121: 131-158.

Wagner, Max L. 1955. Expletive Verbalformen in den Sprachen des Mittelmeers. Romanische Forschungen 67: 1-8.

Wallace, Rex. 1985. Volscian sistiatiens. Glotta 63: 93-101.

Warner, Natasha, Andrea Weber. 2001. Perception of Epenthetic Stops. Journal of Phonetics 29: 53-87.

Weiss, Michael. 1998. On Some Problems of Final Syllables in South-Picene. In: J. Jasanoff, H. C. Melchert, L. Oliver (eds.). Mír Curad. Studies in Honour of Calvert Watkins: 703-715. Innsbruck: Institut für Sprachwissenschaft der Universität Innsbruck.

Weiss, Michael. 2009. An Outline of the Historical and Comparative Grammar of Latin. Ann Arbor / New York: Beech Stave Press.

Weiss, Michael. 2010. Language and Ritual in Sabellic Italy. The Ritual Complex of the Third and Fourth Tabulae Eugubinae, Leiden: Brill.

Weiss, Michael. 2017. An Italo-Celtic Divinity and a Common Sabellic Sound Change. Classical Antiquity 36: $270-289$. Weiss, Michael. Forthc. Pig, Cake and Sun: Observations on the iúvila Inscriptions. (To appear in a Festschrift). Willi, Andreas. 2010. To be or not to be: the Latin Perfect in -v-. Historische Sprachforschung 122: 228-247.

WOU = Untermann, Jürgen. 2000. Wörterbuch des Oskisch-Umbrischen. Heidelberg: Carl Winter Universitätsverlag. Zair, Nicholas. 2012. The Reflexes of the Proto-Indo-European Laryngeals in Celtic. Leiden: Brill.

Zair, Nicholas. 2016. Oscan in the Greek Alphabet. Cambridge University Press.

Б. М. Проспер. Окончания множественного числа аккузатива в сабельских языках и развитие индоевропейских сибилянтов в италийской ветви

Цель настоящей работы - прояснить особенности фонетического и фонологического развития сибилянтов и кластеров, содержащих сибилянты, в италийских языках, с особым упором на рефлексы сочетаний /ns/ и /rs/ в различных позициях. В статье предлагается новая интерпретация для целого ряда сабельских слов и предложений (в первую очередь относящихся к оскскому языку и одному из его диалектов - маррукинскому). В приложении дается новое прочтение «опийской» («до-самнитской») надписи Ниумсиса Тануниса.

Ключевые слова: индоевропейское языкознание; сабельские языки; древняя Италия; общая фонетика. 